\title{
La retirada de Estados Unidos del Plan de Acción Integral Conjunto y la reimposición de sanciones a Irán: aspectos jurídicos y políticos
}

\author{
The United States withdrawal from the Joint Comprehensive Plan \\ of Action and the reimposition of sanctions on Iran: political \\ and legal issues
}

\author{
Pilar Pozo SERRANo \\ Profesora Titular de Derecho Internacional Público y Relaciones Internacionales \\ Universidad de Valencia
}

Pilar.Pozo@uv.es

RECIBIDO EL 15 DE ENERO DE 2018 / ACEPTADO EL 14 DE FEBRERO DE 2019

Resumen: La retirada unilateral por parte de Estados Unidos del PAIC, el acuerdo nuclear adoptado en 2015, suscita problemas relevantes desde la perspectiva del Derecho Internacional. El PAIC no es un instrumento vinculante, pero el recurso a una resolución del Consejo de Seguridad para dotarlo de operatividad ha suscitado diferentes interpretaciones sobre la naturaleza del PAIC y la valoración jurídica de la retirada unilateral por parte de Estados Unidos. El recurso de Irán a la Corte Internacional de Justicia puede dar lugar a un pronunciamiento judicial acerca de la licitud de algunas sanciones de Estados Unidos. El trabajo concluye que la retirada del PAIC por Estados Unidos es lícita, ya que la resolución 2231 (2015) podría haber debilitado la posición del régimen de sanciones de Estados Unidos previo, que contaba con el respaldo de resoluciones del Consejo ahora derogadas en virtud de dicha resolución.

Palabras clave: Estados Unidos, sanciones, Consejo de Seguridad, Irán, PAIC

\begin{abstract}
This paper examines some issues raised by the United States withdrawal from the Joint Comprehensive Plan of Action (JCPOA) related to Iran's nuclear program. The JCPOA is a nonbinding document, there has been some debate about the effect of the subsequent U.N. Security Council resolution endorsing the document on its legal status and on the US faculty of unilaterally withdrawing from the plan of action. Iran brought a case before the International Court of Justice questioning the legality of the reintroduction of U.S sanctions, the Court could eventually address the issue in later phases. This paper concludes that U.S withdrawal is legal from an international law perspective. Security Council resolution 2231 (2015) terminates prior S.C. resolutions imposing sanctions on Iran, as a result it could have weakened US position depriving its sanction regime of the support provided by previous resolutions.
\end{abstract}

Keywords: United States, sanctions, Security Council, Iran, JCPOA

\begin{abstract}
Sumario: I. INTRODUCCIÓN. II. EL PLAN DE ACCIÓN INTEGRAL CONJUNTO: DEBATE EN TORNO A SU NATURALEZA JURÍDICA. II 1. Plan de Acción Integral Conjunto: objetivos, contenido y naturaleza. Il.1.1. Estructura y contenido del Plan de Acción. II.1.2. La naturaleza jurídica del PAIC según el derecho interno de Estados Unidos. II.1.3. La aprobación del PAIC mediante la resolución 2231 (2015) del Consejo de Seguridad: repercusiones. III. RETIRADA UNILATERAL DEL PLAN DE ACCIÓN POR ESTADOS UNIDOS: REACCIÓN INTERNACIONAL Y VALORACIÓN JURÍDICA. III. 1. El camino hacia la retirada del PAIC. III.2. Valoración jurídica de la retirada del acuerdo desde la perspectiva del derecho de Estados Unidos. III. 3. La retirada del PAIC por Estados Unidos desde la perspectiva del Derecho Internacional: alcance de la resolución 2231 (2015). IV. EL EXAMEN DE LA LEGALIDAD DE LAS SANCIONES DE ESTADOS UNIDOS POR LA CORTE INTERNACIONAL DE JUSTICIA. IV. 1. La competencia prima facie de la Corte para conocer el caso. IV. 2. Plausibilidad de los derechos cuya protección se solicita y su conexión con las medidas adoptadas. IV. 3. La existencia de un riesgo de un daño irreparable y urgencia. IV.4. Indicación de medidas provisionales y distanciamiento adicional de la Corte por parte de Estados Unidos. V. CONCLUSIONES.
\end{abstract}




\section{INTRODUCCIÓN}

E 1 régimen de sanciones económicas ${ }^{1}$ adoptadas contra Irán desde el año 2006, en conexión con su programa nuclear, ha sido considerado como uno de los más severos adoptados frente a un Estado por la comunidad internacional ${ }^{2}$. En el caso específico de Estados Unidos, el régimen de sanciones contra Irán probablemente sea también el más complejo. Son sanciones anteriores a las adoptadas por Naciones Unidas y no se limitan a las actividades relacionadas con el programa nuclear de Irán ${ }^{3}$.

Irán puso en marcha su programa nuclear en 1997, con fines exclusivamente civiles según las declaraciones oficiales. En el año 2002, el descubrimiento de dos centrales nucleares secretas y la constatación del avanzado estado del programa suscitaron amplia preocupación internacional ${ }^{4}$. Diferentes iniciativas

1 Excede los límites del trabajo entrar en el análisis de la noción de sanción. La literatura al respecto es abundante, para una revisión relativamente reciente, vid. RUYs, T., «Sanctions, Retorsions and Countermeasures: Concepts and International Legal Framework», en L. Van Den Herik (ed.), Research Handbook on UN Sanctions and International Law, Edward Edgar Publishing, Cheltenham, 2017, pp. 19-50. El término no constituye un concepto jurídico preciso en Derecho internacional. La noción no aparece en la Carta de la ONU, pero algunas resoluciones del Consejo de Seguridad sí lo utilizan y el término se encuentra ampliamente extendido para referirse a los comités encargados de la aplicación de las medidas coercitivas aprobadas para diferentes situaciones («comités de sanciones») o para designar a las «sanciones selectivas» (página informativa de Naciones Unidas sobre los comités de sanciones, en http://www.un.org/spanish/sc/ committees/). El uso de la noción también es frecuente en la práctica estatal.

2 En este sentido, véase la declaración de la representante de Estados Unidos ante el Consejo de Seguridad, S. Power, tras la adopción de la resolución 2231 (2015), Naciones Unidas, Documentos Oficiales del Consejo de Seguridad, S/PV.7488, 7488 sesión, 10 de julio de 2015 (en lo sucesivo S/PV. 7488), p. 3; RENNACK, D. E., Iran: U.S. Economic Sanctions and the Authority to Lift Restrictions, Congressional Research Service Report R43311, Library of Congress, Washington D.C., 10 mayo 2018, p. 4.

3 Las sanciones económicas habían sido un elemento central de la política exterior de Estados Unidos hacia Irán desde la Revolución Islámica de 1979 y el asalto a la Embajada estadounidense en Teherán. Durante las dos décadas posteriores Estados Unidos adoptó nuevas sanciones para presionar a Irán con el objeto de que cesara su apoyo a grupos terroristas, por sus actividades desestabilizadoras en la región, por ciberataques contra Estados Unidos, y sanciones selectivas contra miembros del régimen responsables de violaciones de derechos humanos. Para una exposición sintética del conjunto de sanciones estadounidenses, Katzman, K., Iran Sanctions, Congressional Research Service Report RS20871, Library of Congress, Washington D.C., 28 noviembre 2018, disponible en https://crsreports.congress.gov/product/pdf/RS/RS20871/281. El informe especifica las medidas afectadas por el PAIC y el procedimiento para su reimplantación tras la retirada estadounidense.

4 BERMEjo García, R.; GUTIÉRREZ EsPaDA. C., «El programa nuclear iraní en el ojo del huracán», REDI, vol. 57, n.1, pp. 105-119. 
diplomáticas, bajo la égida de Estados Unidos, condujeron finalmente a la adopción de la resolución del Consejo de Seguridad 1737 (2006), de 27 de diciembre $^{5}$. Contando con el respaldo de estas resoluciones, Estados Unidos encabezó esfuerzos internacionales para aislar la economía iraní. En una primera etapa las sanciones no parecieron hacer mella en Irán, que comenzó a producir uranio con un nivel más elevado de enriquecimiento en 2010. En respuesta, la resolución 1929 (2010) de 9 de junio, abrió la puerta a sanciones dirigidas contra los principales sectores civiles de la economía iraní, tras determinar que tales sectores posibilitaban el desarrollo del programa nuclear de Irán ${ }^{6}$.

La economía de Irán, plenamente integrada en el sistema del comercio y de las finanzas internacionales, representaba un área sobre la que ejercer presión de modo eficaz ${ }^{7}$. En efecto, el amplio programa de sanciones adoptadas por Estados Unidos, la Unión Europea y demás Estados provocó un deterioro significativo en la economía de Irán $^{8}$, factor que se ha considerado decisivo para su participación en las negociaciones conducentes a la adopción del Plan de Acción Integral Conjunto (PAIC). El PAIC fue valorado mayoritariamente como un éxito de la diplomacia multilateral'. También tuvo detractores,

5 Era la primera resolución que decidía sanciones dirigidas específicamente contra Irán por el desarrollo de un programa nuclear y de armas de destrucción masiva. Las resoluciones anteriores del Consejo de Seguridad, por ejemplo 1540 (2004), de 28 de abril, habían adoptado sanciones contra actividades de proliferación de armas nucleares, químicas y biológicas en general, sin un destinatario específico. Tras la resolución 1737 (2006), entre 2006 y 2007 el Consejo de Seguridad adoptó nuevas resoluciones 1747(2007) y 1803 (2008) que ampliaban las sanciones por el programa nuclear y la infraestructura de armas de destrucción masiva de Irán. Un análisis detallado de las medidas adoptadas por el Consejo de Seguridad en relación con el programa nuclear iraní es ofrecido en el trabajo de BERMEjo GARCÍA, R.; GUTIÉRREZ ESPADA, C., «Del programa nuclear de la República Islámica de Irán y de su evolución (política y derecho)», AEDI, vol. 31, 2015, pp. 7-63.

6 La resolución 1929 (2010) establecía asimismo severas restricciones al programa de misiles balísticos iraní y un embargo al comercio de armas con Irán.

7 RenNaCK, D. E., Iran: U.S. Economic Sanctions and the Authority to Lift Restrictions, Congressional Research Service Report R43311, Library of Congress, Washington D.C., 10 mayo 2018, p. 4.

8 Se calcula que durante los años 2012-2015 la economía iraní experimentó un crecimiento negativo de un 9\% anual (KaTZMAN, K., Iran Sanctions, op. cit., p. 1). Conforme a una estimación del Secretario del Tesoro de Estados Unidos, en 2015 la economía iraní era entre un 15 y un 20 por ciento menor de lo que podría haber sido en caso de que las sanciones no hubieran sido endurecidas en 2012. La inflación alcanzó cerca de un 40 por ciento entre 2012 y 2014 (LAUB, Z., «International Sanctions on Iran», Council on Foreign Relations Backgrounder, 15 de julio de 2015, disponible en https://www.cfr.org/backgrounder/international-sanctions-iran).

9 Es la valoración que ofrecen, entre otros: WECKEL, P., «L'accord du 14 juillet sur le programme nucléaire iranien», Bulletin Sentinelle, $\mathrm{n}^{\circ}$ 442, 12 de julio de 2015; Joyner, D., Iran's Nuclear Program and International Law: From Confrontation to Accord, Oxford University Press, 2016, vid. capítulo 7 relativo al PAIC, pp. 221-246. 
opuestos radicalmente a los principios fundamentales sobre los que descansaba el acuerdo ${ }^{10}$. Por último, sin ignorar sus logros, algunos analistas han cuestionado algunos aspectos de fondo y de procedimiento ${ }^{11}$.

La llegada al poder de Trump ha operado una transformación de los objetivos de la política exterior de Estados Unidos en diferentes ámbitos. En particular, el cambio de estrategia en relación con Irán había sido un aspecto central en su campaña. La retirada unilateral de Estados Unidos del PAIC, el 8 de mayo de 2018, no supuso realmente una sorpresa, había sido precedida de númerosos avisos, aunque no por ello dejaba de representar un duro golpe para los demás participantes en el PAIC ${ }^{12}$. En primer lugar para Irán, pero también para los tres países europeos implicados (Alemania, Francia y Reino Unido).

El presente trabajo aborda algunos de los problemas que, desde la perspectiva del Derecho internacional, suscita la retirada unilateral del PAIC. Una cuestión prioritaria ha sido determinar la naturaleza del PAIC, para dilucidar si el Presidente tenía competencia para desvincularse del mismo sin desencadenar por ello la responsabilidad internacional de Estados Unidos. En el trabajo se ha analizado, igualmente, la forma del acuerdo, su contenido y su peculiar estructura, elementos que revelan el papel determinante jugado por los factores políticos y diplomáticos concurrentes. La atención a la evolución de los acontecimientos relacionados con la retirada de Estados Unidos del PAIC, pone de manifiesto los problemas derivados de un régimen de sanciones inadecuadamente concebido. Finalmente, el recurso de Irán a la Corte Internacional de Justicia solicitando -y obteniendo- una orden en indicación

10 Como señalan los profesores Bermejo García y Gutiérrez Espada, Israel desplegó una intensa campaña en contra de la adopción del acuerdo y mostró su profundo rechazo cuando el PAIC fue adoptado, vid. BERMEjo GARCÍA, R.; GutiÉRREZ EsPaDA, C., «Del programa nuclear...», op. cit., p. 43.

11 M. Singh, por ejemplo, frente al énfasis en la diplomacia multilateral afirma el papel central de las negociaciones bilaterales, conducidas en paralelo por Estados Unidos e Irán, en la configuración del texto del acuerdo. El autor se muestra crítico con otros aspectos del acuerdo, en particular ve en la aprobación de la resolución 2231 (2015) una manifestación de unilateralismo por parte de Estados Unidos que habría instrumentalizado el Consejo de Seguridad para eludir la oposición interna a la adopción del acuerdo. Vid. M. SINGH, «The International Order and Nuclear Negotiations with Iran», Texas National Security Review, vol. 1, n. 2, 2018, pp. 105-114, p. 112.

12 No se puede ignorar el interés económico de un amplio número de Estados en acceder al mercado iraní, el restablecimiento de las sanciones también afectaba negativamente a su economía. En este sentido, véase, MoArefy, S, «Partially Unwinding Sanctions: The Problematic Construct of Sanctions Relief in the JCPOA», SSRN Paper (2016), disponible en: https://ssrn.com/abstract $=2777035$. 
de medidas provisionales, abre un nuevo capítulo ante la eventualidad de un pronunciamiento judicial que se pronuncie sobre la licitud de algunas de las medidas adoptadas por Estados Unidos.

\section{EL PLAN DE ACCIÓN INTEGRAL CONJUNTO: DEBATE EN TORNO A SU NATURALEZA JURÍDICA}

El análisis de la retirada unilateral del PAIC por parte Estados Unidos, exige detenerse brevemente en la naturaleza jurídica del acuerdo, prestando atención a las circunstancias que rodearon su adopción, tanto a nivel interno de Estados Unidos, como en el plano internacional.

\section{II.1. Plan de Acción Integral Conjunto: objetivos, contenido y naturaleza jurídica}

El PAIC fue concluido en 2015, tras varios años de negociaciones entre Irán y un grupo de seis Estados (el denominado P5+1) integrado por los cinco miembros permanentes del Consejo de Seguridad y Alemania junto con la Unión Europea.

El objetivo esencial del Plan de Acción es intentar impedir que Irán se dote de armas nucleares. Con este fin establece una serie de restricciones materiales a las actividades iraníes y mecanismos de transparencia y verificación que, de ser cumplidos efectivamente, tendrían el efecto de imposibilitar que Irán produjera material fisionable para armas nucleares en sus instalaciones nucleares durante un periodo de entre 10 y 15 años. Durante este periodo, los mecanismos previstos en la PAIC incrementarían las posibilidades de detectar cualquier intento de construir instalaciones secretas o producir material fisible por parte de Irán. Trascurridos los plazos de 10 a 15 años previstos en el Plan de Acción finalizarían las restricciones a las actividades iraníes y expirarían la mayoría de las disposiciones relativas a la verificación y control. A partir de ese momento, Irán podría ampliar sus instalaciones nucleares y tendría más facilidad para desarrollar nuevamente actividades encaminadas a dotarse de armamento nuclear ${ }^{13}$. No

13 Samore, G. (ed.), The Iran Nuclear Deal. A Definitive Guide, Belfer Center for Science and International Affairs, Harvard College, Cambride (Ma), New Foreword November 2017 (original publication August 2015), p. 4. 
obstante, en palabras de la representante de Estados Unidos ante el Consejo de Seguridad, la aplicación del PAIC habría tenido el efecto de cuadriplicar el tiempo requerido para producir la cantidad necesaria de uranio adecuado para la fabricación de un arma nuclear ${ }^{14}$. Irán reiteró en el Plan de Acción su compromiso de no desarrollar ni adquirir armas nucleares, de acuerdo con sus obligaciones en virtud del TNP y del Acuerdo de salvaguardias entre Irán y el OIEA.

En caso de que Irán respetara los límites establecidos en el acuerdo para las actividades relacionadas con el programa nuclear, el grupo $\mathrm{E} 3 / \mathrm{UE}+3{ }^{15}$ procedería en contrapartida al levantamiento de todas las sanciones impuestas por la ONU y de las sanciones económicas de Estados Unidos y la Unión Europea relacionadas con el programa nuclear de Irán ${ }^{16}$.

\section{II.1.1. Estructura y contenido del Plan de Acción}

El Plan de Acción es un texto extenso y complejo, el acuerdo principal va acompañado de cinco anexos. Adicionalmente, para poder aplicarlo fue refrendado por la resolución 2231 (2015) de 20 de julio, del Consejo de Seguridad que iba acompañada, a su vez, de dos anexos: el propio PAIC, por un lado (Anexo A) y una Declaración conjunta del P5+1 (Anexo B).

El PAIC comienza con un Prefacio en el que enuncia la finalidad perseguida por el Acuerdo en términos muy generales ${ }^{17}$. A continuación, sigue un preámbulo acompañado de disposiciones generales que, tras reiterar los obje-

14 Naciones Unidas, Documentos Oficiales del Consejo de Seguridad, S/PV.7488, 7488 sesión, 10 de julio de 2015, p. 2.

15 En función de la fuente se utilizan las expresiones «P5+1 conjuntamente con la UE» o $\ll \mathrm{E} 3+\mathrm{UE}+3 »$ (Reino Unido, Francia y Alemania; Unión Europea; Estados Unidos, China y Federación rusa) que sirven para designar el mismo grupo.

16 PAIC, Preámbulo, párrafo 4.

17 En esencia, el prefacio destaca que el Acuerdo modifica el modo de enfocar el problema del programa nuclear iraní. Por un lado, Irán ve reconocida su pretensión de dotarse de un programa nuclear «exclusivamente pacífico, autóctono y acorde con las consideraciones científicas y económicas, de conformidad con el PAIC y con miras a fomentar la confianza y alentar la cooperación internacional» (vid. S/RES/2231(2015), Anexo A: Plan de Acción Integral Conjunto (PAIC), Viena, 14 de julio de 2015, Prefacio, párrafo 1, p. 8). Previamente, Irán había renunciado expresamente a desarrollar o dotarse por cualquier medio de armas nucleares, «jamás y bajo ninguna circunstancia» (ibid., parr. 1). Por su parte, los integrantes del E3/U3+3, en la medida en que el cumplimiento por Irán de los compromisos asumidos generara la suficiente confianza en la naturaleza pacífica del programa iraní, se comprometían a levantar todas las sanciones relacionadas con el programa nuclear de Irán (ibid., parr. 3 y 4). El Acuerdo, por lo tanto, no afectaría a las sanciones que pesan sobre Irán por motivos no referidos a su programa nuclear. 
tivos del PAIC adelanta algunos aspectos del régimen ${ }^{18}$, remite a los anexos del Acuerdo para la regulación de los detalles técnicos ${ }^{19} \mathrm{y}$, sobre todo, se refiere a lo que constituye la premisa imprescindible para la puesta en funcionamiento: la adopción de una resolución mediante la que el Consejo de Seguridad haga suyo el PAIC ${ }^{20}$.

La parte dispositiva del acuerdo es introducida en los siguientes términos: «Irán y el E3/UE+3 tomarán las siguientes medidas de cumplimiento voluntario dentro de los plazos detallados en el presente PAIC y sus anexos». En esta parte del documento se enuncian, en líneas generales, los compromisos que asume Irán relativos a las actividades en el ámbito de la energía nuclear así como las medidas de inspección para fomentar la confianza. Quedan esbozados igualmente los compromisos en materia de sanciones por parte del E3/ UE+3, las fases de aplicación del Plan y un mecanismo de solución de controversias $^{21}$. Los compromisos de las Partes son regulados de manera detallada en los Anexos al PAIC. El Anexo I enuncia los asumidos por Irán en materia nuclear y de actividades de verificación ${ }^{22}$. El Anexo II recoge los compromisos de las otras partes en materia de levantamiento de sanciones ${ }^{23}$.

18 Se mencionan, entre otros aspectos, la constitución de una Comisión Conjunta para supervisar el cumplimiento del PAIC, la participación del Organismo Internacional de la Energía Atómica (OIEA) asumiendo funciones de verificación o que las disposiciones del Acuerdo afectan exclusivamente a las partes que lo han adoptado (Preámbulo, par. ix, x y xi).

19 Préambulo, xii).

20 Preámbulo, xiv).

21 S/RES/2231(2015), Anexo A, p. -11-21.

22 El Anexo I del PAIC regula de modo detallado las medidas relacionadas con la energía nuclear, agrupándolas en diferentes categorías (Reactor de investigación de agua pesada de Arak; planta de producción de agua pesada; otros reactores; Actividades de reprocesamiento de combustible gastado; Capacidad de enriquecimiento; Investigación y desarrollo sobre centrifugadoras; Planta de enriquecimiento de combustible de Fordow; Otros aspectos de las actividades de enriquecimiento; Existencias y combustibles de uranio; Fabricación de centrifugadoras; Protocolo Adicional [del Acuerdo de Salvaguardias iraní] y versión modificada de la sección 3.1; Cuestiones preocupantes pasadas y presentes; Tecnologías modernas y presencia del OIEA a largo plazo; Transparencia en relación con el concentrado de mineral de uranio; Transparencia en relación con el enriquecimiento; Acceso; Transparencia en la fabricación de componentes para centrifugadoras; Otras actividades de separación de isótopos de uranio; Actividades que podrían contribuir al diseño y desarrollo de un dispositivo explosivo nuclear) y acompañando un apéndice sobre el diseño conceptual del reactor de Arak (S/RES/2231(2015), Anexo I, pp. 22-39).

23 El Anexo II del PAIC, enuncia los compromisos relativos a las sanciones asumidos por la Unión Europea y por Estados Unidos. En lo que a la Unión Europea concierne, al acuerdo agrupa las sanciones adoptadas en respuesta al programa nuclear en las siguientes categorías: Medidas financieras, bancarias y relacionadas con los seguros, Sectores del petróleo, el gas y los productos petroquímicos; Sectores de expedición, construcción naval y transporte; Oro, otros metales pre- 
En virtud del Anexo II, Estados Unidos se comprometía a «dejar de aplicar todas las sanciones relacionadas con la energía nuclear» enumeradas en disposiciones especificadas y que comprendían, entre otras, medidas financieras y bancarias así como comercio de petróleo y derivados ${ }^{24}$. Estados Unidos se había comprometido a poner fin a las principales sanciones económicas que afectaban al sector financiero y energético de Irán, así como al sector bancario, si bien el acceso de estos sectores al mercado estadounidense seguía mayoritariamente excluido ${ }^{25}$. En efecto, el levantamiento generalizado de sanciones se refería sólo a las «sanciones secundarias», es decir las dirigidas contra personas y entidades no estadounidenses. Para las personas estadounidenses y las entidades extranjeras bajo su control, seguía vigente la prohibición general de las transacciones permitidas por el PAIC, salvo autorización de las agencias

ciosos, billetes y monedas; Medidas relacionadas con la proliferación nuclear; Metales Programas informáticos; Armas; Inclusión de personas, entidades y organismos en la lista (congelación de activos y prohibición de visados). Las disposiciones del Anexo especifican asimismo un conjunto de medidas relacionadas con los seguros y los sectores del petróleo, gas y productos petroquímicos que, como consecuencia del levantamiento de las sanciones económicas y financieras de la UE, estarían permitidas en lo sucesivo (pp. 39-44). Los apéndices I y II del Anexo II contiene las listas de personas y entidades afectadas por las medidas restrictivas adoptadas por la UE.

24 PAIC, art. 21-25. El Anexo detalla las sanciones de Estados Unidos que quedarían levantadas comprendidas en las siguientes categorías: Medidas financieras y bancarias; Medidas relativas a los seguros; Sectores de la energía y los productos petroquímicos; Sectores de expedición, construcción naval y puertos; Oro y otros metales preciosos Programas informáticos y metales; Sector automotor Designaciones y otras listas de sanciones Medidas relacionadas con la proliferación nuclear y otras medidas comerciales. Se explicita asimismo que el levantamiento de dichas sanciones, llevaría aparejado de las sanciones impuestas a personas no estadounidenses en conexión con las actividades mencionadas (pp. 47-54). Los Apéndices III y IV, enumeran las instituciones financieras iraníes y las personas y entidades identificadas como pertenecientes al Gobierno de Irán y demás entidades y personas, y sus bienes, afectados por las sanciones de Estados Unidos (ibid., pp. 75-97).

25 El hecho de que el sistema de sanciones estadounidenses permaneciera vigente en su mayor parte contribuyó a que la recuperación económica iraní fuera más lenta de lo esperado. No solo por la exclusión del importante mercado estadounidense. Varios factores contribuían a crear un clima de incertidumbre poco atractivo para realizar transacciones con Irán. Por un lado, la persistencia de sanciones a quienes hubieran realizado transacciones con personas y entidades incluidas en otras listas de sanciones (aunque hubieran sido eliminadas de la lista de sanciones relativas al programa nuclear). Por otro, la incertidumbre que la situación política en Irán y Estados Unidos generaban acerca del futuro del acuerdo. En este sentido, SAMORE, G. (ed.), The Iran Nuclear Deal..., op. cit., p. 64; NEPHEW, R., «The Hard Part: The Art of Sanctions Relief», The Washington Quarterly, 2018, vol. 41, n. 2, pp. 63-77, en pp. 68-69. El autor señala que, tras la conclusión del PAIC, el Secretario de Estado John Kerry entró en contacto con bancos europeos y asiáticos para impulsar la restauración de relaciones con Irán, obteniendo una respuesta negativa por parte de algunos de los grandes bancos que consideraban el PAIC como un fundamento demasiado frágil. 
pertinentes de Estados Unidos $^{26}$. Las sanciones primarias seguían aplicándose en su mayor parte ${ }^{27}$.

El Anexo III del PAIC, enuncia los compromisos de las Partes en materia de cooperación nuclear civil ${ }^{28}$; el Anexo IV regula el establecimiento, composición y funciones de la Comisión conjunta ${ }^{29}$ y el Anexo $\mathrm{V}$ detalla el plan de aplicación ${ }^{30}$.

La resolución 2231 (2015), incorporaba en el Anexo B una Declaración de todos los estados negociadores del acuerdo, salvo Irán, mediante la que condicionaban su participación en el PAIC a la previa adopción de una resolución por parte del Consejo de Seguridad ${ }^{31}$.

\section{II.1.2. La naturaleza jurídica del PAIC según el derecho interno de Estados Unidos}

La naturaleza jurídica del PAIC, el carácter obligatorio o no de los compromisos adquiridos en virtud del mismo, ha sido objeto de un intenso debate y de numerosos análisis en Estados Unidos.

26 Anexo II del PAIC, art. 4, nota 6.

27 Entre las sanciones primarias levantadas, el acuerdo incluye la venta de aeronaves comerciales de pasajeros, piezas de repuesto y servicios conexos (Anexo II del PAIC, art. 5.1.1), y la importación de alfombras y determinados productos alimenticios (art. 5.1.3).

28 S/RES/2231(2015), Anexo III del PAIC, pp. 98-104.

29 Ibid., Anexo IV del PAIC, pp. 105-111

30 Ibid., Anexo V del PAIC, pp. 112-117. El calendario previsto establece la secuencia a la que deben ajustarse las Partes en el cumplimiento de sus compromisos: el día de finalización marca la primera etapa, a la que siguen el día de aprobación, día de aplicación, día de transición y día de terminación de la resolución del Consejo de Seguridad que refrenda el Plan de Acción.

31 Vid. S/RES/2231(2015), Anexo B (pp. 117-123). El anexo B enuncia también compromisos de las Partes no relacionados con las actividades nucleares. Estados Unidos había preferido no incluir en el PAIC algunos de los aspectos más controvertidos de las negociaciones, por ejemplo el referente al levantamiento del embargo sobre el comercio de armas convencionales y la mitigación de las restricciones al desarrollo e importación de tecnología relativa a misiles balísticos. Las disposiciones acordadas en esos ámbitos fueron incluidas en la resolución 2231 (2015) aunque no en el cuerpo principal de la resolución, sino en el anexo B. El régimen establecido en la resolución sobre estos dos aspectos comporta una notable disminución de las restricciones establecidas en resoluciones previas. Al parecer, las disposiciones obedecen al compromiso alcanzado para superar el impasse provocado por la insistencia de Irán, respaldada por Rusia, en el levantamiento inmediato de todas las restricciones sobre armas convencionales y misiles balísticos. La Declaración prevé, en cambio, la persistencia de embargo y restricciones durante un periodo de cinco y ocho años, respectivamente (LYNCH, C.; HUDSON, J., «Obama Turns to U.N to Outmaneuver Congress», Foreign Policy, 15 de julio, 2015, disponible en http://foreignpolicy. com/2015/07/15/obama-turns-to-u-n-to-outmaneuver-congress-iran-nuclear-deal/). 
Un primer elemento a considerar es que, formalmente, el PAIC no constituye un Tratado internacional: la conformidad manifestada por las partes respecto a su contenido no se tradujo en los actos previstos para la conclusión de un Tratado en el Convenio de Viena sobre el Derecho de los Tratados, ni en los derechos internos de los Estados participantes en la negociación ${ }^{32}$. El PAIC no fue firmado, no contiene disposiciones relativas a la ratificación y entrada en vigor, simplemente fue anunciado conjuntamente por la Representante de la Unión Europea y el representante de Irán ${ }^{33}$.

La postura del Ejecutivo estadounidense había sido clara al respecto, el Plan de Acción no constituía un Tratado internacional sino un compromiso político. La decisión presidencial de negociar con Irán contaba con numerosos detractores dentro y fuera del Congreso. El PAIC fue adoptado como compromiso político y no como un tratado internacional para que su adopción no se viera supeditada a la poco probable aprobación de un Senado con mayoría republicana ${ }^{34}$. Una pre-

32 En el caso de Reino Unido, vid. O'Kane, M., EU Scrutiny Committee urges debate on JCPOA: «The House of Commons European Scrutiny Committee has urged the UK Government to hold a parliamentary debate on the JCPOA nuclear deal as soon as possible. The Committee had said in early September that since 2 months had passed since the agreement of the JCPOA there should be a debate on its possible repercussions, but that debate had not been arranged. In the meantime, the committee did not take issue with the Minister for Europe David Lidington having agreed to the EU's measures introduced to implement the JCPOA». (Disponible en https://europeansanctions.com/2015/11/18/eu-scrutiny-committee-urges-debate-on-jcpoa/.

33 JoYner, D., Iran's Nuclear Program and International Law: From Confrontation to Accord, Oxford University Press, 2016, pp. 221-246 (el capítulo 7 relativo al PAIC se encuentra disponible como Studies Research Paper No. 2837095, SSRN: https://ssrn.com/abstract=2837095)

34 Los detractores de la negociación del PAIC por Obama propusieron la adopción de legislación que supeditara la conclusión de cualquier acuerdo con Irán a la previa aprobación del Congreso. Ante la presentación de una propuesta legislativa en este sentido, D. McDnough, asistente del Presidente, dirigió una carta al Senador B. Corker, Presidente del Comité del Senado sobre Asuntos Exteriores, en la que además de comunicar que el Presidente haría uso de su facultad de vetar la ley en caso de que su tramitación siguiera adelante, justifica la competencia del Presidente para negociar el PAIC aduciendo que se trataba de un acuerdo no vinculante (en otro momento utiliza el término de un compromiso político), un elemento esencial de la diplomacia internacional estadounidense no necesitado de la aprobación del Congreso. La carta aduce en su respaldo ejemplos de la práctica estadounidense sobre conclusión de compromisos políticos, también en materias sensibles de seguridad nacional (vid. fragmentos relevantes de la carta de D. McDonough, de 14 de marzo de 2015, de reproducidos en Guymon, C. D. (ed.) Digest of United States Practice in International Law, Office of the Legal Adviser United States Department of State, 2015, pp. 123124). La adopción de la Ley para Revisar el Acuerdo Nuclear con Irán (Iran Nuclear Agreement Review Act) firmada por el presidente Obama el 22 de mayo de 2015, permitió poner fin a este pulso entre la Administración y el Congreso (en este sentido, vid. WECKEL, P. «Etats-Unis, la loi sur l'examen parlementaire de l'accord nucléaire avec l'Iran», Bulletin Sentinelle, n. 435, 24 de mayo de 2015). Sobre el contenido de esta ley véase lo señalado en la n. 48. 
ocupación compartida por el gobierno iraní: el carácter extremadamente sensible del acuerdo y la oposición manifestada por los sectores políticos más duros recomendaban dejar la adopción del texto fuera del alcance del Parlamento. Se ha sugerido que esta forma, la del acuerdo político, se ajustaba mejor a los mecanismos de revisión previstos por el Plan de acción, necesitados de mayor flexibilidad que la permitida por el Derecho internacional e interno en materia de conclusión de tratados ${ }^{35}$.

La importancia de la forma escogida para el acuerdo va más allá de la cuestión meramente procedimental, alcanza también a la mentalidad con la que se abordan los procesos de negociación. En este sentido se ha señalado que los Estados adoptan un enfoque marcadamente más conservador y restrictivo en la negociación de los tratados que en la de los acuerdos políticos. En estos últimos, por muy serio que sea el compromiso de las partes con lo acordado, el incumplimiento aparece siempre como una última opción en la medida en que no desencadena la responsabilidad internacional ni otras consecuencias jurídicas $^{36}$. La negociación de determinados Tratados, por ejemplo sobre reducción de armamento entre Estados Unidos y Rusia, resultan reveladores de la importancia conferida por las Partes a la forma del acuerdo. Tanto en el caso del Tratado SALT II y del SORT, Estados Unidos había propuesto adoptar un Acuerdo del Ejecutivo y del Congreso pero el Ministro de Asuntos Exteriores soviético, en el primer caso, y el Presidente Putin en el segundo, insistieron en que Estados Unidos lo sometiera al procedimiento de los Tratados. El interés puede obedecer a motivos variados. La necesidad de aprobación por mayoría cualificada del Senado, en el caso de los Tratados, puede ser interpretado por la otra parte como señal de un mayor grado de compromiso, o de mayor perdurabilidad, en la medida en que las mayorías en el Senado suelen ser más estables ${ }^{37}$. El texto del Plan de

35 Véanse las explicaciones de la Subsecretaria de Estado para Asuntos Exteriores durante la Administración Obama, W. R. Sherman, que había encabezado el equipo negociador estadounidense Sherman, W. R., «How We Got the Iran Deal and Why We'll Miss It», Foreign Affairs, vol. 97, n. 5, sep-oct 2018, pp. 186-197. Con carácter general, el derecho estadounidense confiere amplia flexibilidad al Presidente para adoptar o levantar sanciones con agilidad, entendiendo que esta capacidad de respuesta a las circunstancias cambiantes es esencial para la eficacia de las sanciones. En este sentido, RENNACK, D. E., Iran: U.S. Economic Sanctions and the Authority to Lift Restrictions, Congressional Research Service Report R43311, Library of Congress, Washington D.C., 10 mayo 2018, p. 5, disponible en https://fas.org/sgp/crs/mideast/R43311.pdf).

36 JoYner, D., Iran's Nuclear Program..., op. cit., pp. 228-230.

37 Nyarko, J., «Giving the Treaty a Purpose: Comparing the Durability of Treaties and Executive Agreements», AfIL, vol. 113, n. 1, 2019, pp. 54-89, p. 56. El trabajo realiza un estudio estadís- 
Acción Integral Conjunto corrobora explícitamente su naturaleza no vinculante, al caracterizar los compromisos formulados como «medidas de cumplimiento voluntario ${ }^{38}$ manifiesta de modo inequívoco la intención de las Partes al respecto ${ }^{39}$.

Una valoración con la que coincidieron numerosos analistas y que probablemente resulte adecuada si se toma en consideración el PAIC por sí mismo $^{40}$. No obstante, la adopción del PAIC suscitó debates acerca de su naturaleza jurídica. Pese a la reiterada afirmación de su carácter no vinculante, el PAIC no parecía estar concebido como tal, pues enunciaba compromisos a medio y largo plazo, dirigidos a limitar la capacidad de actuación futura de las Partes ${ }^{41}$. Obama se encontraba a un año de finalizar su segundo mandato y se suscitaba el interrogante de su obligatoriedad para la siguiente Administración.

Si se consideraba que el PAIC era un acuerdo no vinculante, desde la perspectiva del Derecho internacional no existiría ningún obstáculo para que la Administración Trump se retirara del mismo y restableciera las sanciones previamente adoptadas por Estados Unidos ${ }^{42}$.

tico tomando como muestra los acuerdos vigentes para Estados Unidos entre 1982 y 2012, un número cercano a los 8.000 instrumentos. Los resultados pondrían de manifiesto, a juicio del autor, la mayor durabilidad de los tratados respecto a los acuerdos del Ejecutivo y los acuerdos del Ejecutivo y el Congreso. En concreto, los Tratados concluidos en 1982 tenían un 15 por ciento de posibilidades de terminar en 2012, frente a un 50 por ciento en el caso de los otros acuerdos (ibid., p. 86).

38 S/RES/2231 (2015), p. 11.

39 JoYNER, D., Iran's Nuclear Program and International Law..., op. cit., p. 228.

40 En este sentido, vid. Mulligan, S.P., Withdrawal from International Agreements..., bibliografía citada en nota 169. Otros autores, sin embargo, pusieron de manifiesto una posible desviación del régimen previsto constitucionalmente (en este sentido, RAMSEY, M., «Is the Iran Deal Unconstitutional?», disponible en https://originalismblog.typepad.com/the-originalism-blog/2015/07/ is-the-iran-deal-unconstitutionalmichael-ramsey.html, The Originalism Blog, 15/7/2015), aduciendo que el PAIC debía haber sido aprobado como Tratado, y por consiguiente contar con la autorización del Senado, por mayoría de dos tercios.

41 RAMSEY, M., «Is the Iran Deal Unconstitutional?», op. cit.

42 Lynch, C.; Hudson, J., «Obama Turns to U.N...», op. cit. Los autores reflejan la situación de división existente en el Congreso estadounidense respecto a la adopción del PAIC y las diferentes reacciones suscitadas por la sumisión del acuerdo al Consejo de Seguridad, antes de ser aprobado por el Congreso. Para algunos republicanos la maniobra suponía una «peligrosa subyugación de la soberanía estadounidense» y un insulto a la función de control del Congreso. Para otros miembros del Congreso, la intervención previa del Consejo de Seguridad les evitaba la posibilidad de encontrarse en la incómoda posición de votar una cuestión que podría verse modificada como consecuencia de una resolución del Consejo. 
II.1.3. La aprobación del PAIC mediante la resolución 2231 (2015) del Consejo de Seguridad: repercusiones

Los compromisos que adquirían los integrantes del E3/UE+3 resultaban incompatibles con el régimen de sanciones vigente, establecido por el Consejo de Seguridad mediante una serie de resoluciones vinculantes. La operatividad del Plan de Acción, por lo tanto, estaba supeditada a la previa adopción por el Consejo de Seguridad de una nueva resolución que pusiera fin a todas las disposiciones de las resoluciones previas sobre el programa nuclear iraní. En este sentido, el Preámbulo del Plan de Acción señalaba que los países del E3+3 presentarían un proyecto de resolución al Consejo de Seguridad, en el que éste:

«hará suyo el PAIC, afirmará que su concertación constituye un cambio fundamental en su examen de esta cuestión y expresará su deseo de construir una nueva relación con el Irán. En esa resolución, el Consejo de Seguridad de las Naciones Unidas también dispondrá que el Día de Aplicación se terminarán las disposiciones impuestas en virtud de resoluciones anteriores, que se establecerán restricciones específicas y que el Consejo de Seguridad de las Naciones Unidas concluirá su examen de la cuestión nuclear iraní 10 años después del Día de Aprobación» ${ }^{43}$.

Una de las disposiciones claves del PAIC, de la que dependía el conjunto de compromisos formulados por las partes, se refería a la futura resolución:

«en la que el Consejo de Seguridad de las Naciones Unidas hace suyo el presente PAIC terminará todas las disposiciones de las resoluciones anteriores del Consejo de Seguridad de las Naciones Unidas sobre la cuestión nuclear iraní - 1696 (2006), 1737 (2006), 1747 (2007), 1803 (2008), 1835 (2008), 1929 (2010) y 2224 (2015)— de forma simultánea con la aplicación por el Irán, verificada por el OIEA, de las medidas relacionadas con la energía nuclear convenidas, y establecerá restricciones específicas, como se indica en el anexo V1.» ${ }^{44}$

El Consejo adoptó la resolución 2231 (2015), el 20 de julio, satisfaciendo las previsiones del PAIC y otorgando el respaldo esperado al conjunto de compromisos asumidos por las Partes. La resolución 2231 (2015) incluía dos

43 PAIC; Preámbulo y disposiciones generales, xiv).

44 PAIC, punto 18. 
anexos: el anexo A, que contiene el texto del PAIC junto a sus anexos, y el anexo $\mathrm{B}$, que recoge una Declaración de los integrantes del E3+3. Por medio de esta Declaración, Reino Unido, Francia, Alemania, Federación rusa y Estados Unidos condicionaban su efectiva participación en el PAIC a la adopción por el Consejo de Seguridad de una resolución en los términos señalados por el acuerdo, que señalaba entre otras consideraciones que algunas de las disposiciones de la resolución tenían que ser adoptadas en virtud del Artículo 41 de la Carta ${ }^{45}$. La Declaración señalaba, asimismo, que esa resolución del Consejo debería exigir a todos los demás Estados la adopción de una serie de medidas con el objeto de asegurar la eficacia del PAIC.

El problema sobre la naturaleza jurídica del acuerdo, a juicio de algunos autores, habría quedado superado a partir de la intervención del Consejo de Seguridad que, al «hacer suyo» el acuerdo mediante la resolución 2231 (2015), de 20 de julio, habría modificado los términos de la cuestión, transformando algunas «medidas voluntarias» del PAIC en obligaciones jurídicas ${ }^{46}$.

\section{RETIRADA UNILATERAL DEL Plan DE ACCIÓN POR Estados Unidos: REACCIÓN INTERNACIONAL Y VALORACIÓN JURÍDICA}

Durante la campaña electoral, en 2016, Trump se había pronunciado de modo contundente en contra del PAIC y reiterado su intención de «desmantelar» el acuerdo. Durante su primer año de presidencia, sin embargo, certificó en dos ocasiones -en abril y en julio de 2017- que Irán había cumplido sus obligaciones en virtud del Plan de Acción Integral Conjunto y renovó el levantamiento de las sanciones conforme a lo previsto en el mismo. Trump, de hecho, había ampliado la lista de sanciones suspendidas, el 16 de septiembre de 2017, para dar cumplimiento al PAIC ${ }^{47}$.

45 Vid. S/RES/2231(2015), Anexo B (pp. 117-123). La resolución 2231 (2015), en efecto, se sitúa explícitamente en el marco del artículo 41 y decide que, una vez que el OIEA emita el informe previsto en el PAIC, confirmando que Irán ha cumplido sus compromisos referentes a la energía nuclear, terminará la aplicación de las resoluciones en él enumeradas, vid. par. 7..a).

46 La resolución del Consejo de Seguridad, según la percepción mayoritaria, tendría el efecto de crear para cualquier Presidente la obligación jurídica de cumplir los compromisos del PAIC. En este sentido, entre otros, LYNCH, C.; HUdSON, J., «Obama Turns to U.N...», op. cit.

47 El portavoz del Departamento de Estado, no obstante, subrayó que tal decisión no significaba un refrendo del Plan de Acción por parte de la Administración. La Casa Blanca estaba en proceso de definir su posición respecto al Plan de Acción, tomando en consideración no sólo 


\section{III.1. El camino hacia la retirada del PAIC}

El 13 de octubre de 2017, coincidiendo con el discurso sobre la estrategia de la nueva Administración respecto a Irán, el Presidente declinó efectuar la certificación prevista en la Ley de revisión del Acuerdo Nuclear con Irán ${ }^{48}$ para renovar la suspensión de las sanciones ${ }^{49}$. La negativa a emitir los certificados de cumplimiento no comportaba por sí sola la terminación de la participación de Estados Unidos en el PAIC ni la reinstauración de las sanciones suspendidas ${ }^{50}$. Llegada la fecha prevista para la siguiente certificación, el 12 de enero de 2018, el Presidente rechazó de nuevo certificar el cumplimiento

las actuaciones de Irán contempladas en el PAIC sino el comportamiento iraní en su conjunto, lo que incluía actividades como desarrollo de misiles balísticos, apoyo material y financiero a grupos terroristas dentro y fuera de su territorio, ciberataques contra Estados Unidos, violaciones de derechos humanos y otras actuaciones potencialmente desestabilizadoras de la paz y seguridad internacionales (U.S Department of State, Department Press Briefing, 14 de septiembre de 2017, disponible en https://www.state.gov/r/pa/prs/dpb/2017/09/274084. htm).

48 Act To provide for congressional review and oversight of agreements relating to Iran's nuclear program, and for other purposes, 22.05.2015 (114th Congress, Public Law No: 114-17) La Ley para Revisar el Acuerdo Nuclear con Irán, de 2015, fue adoptada para garantizar cierto control y supervisión de la aplicación del PAIC por parte del Congreso estadounidense. En virtud de la misma, el Presidente debía certificar cada 90 días que Irán estaba aplicando íntegramente el Plan, que no había incurrido en ninguna violación material del Plan de acción ni adoptado medida alguna que supusiera un avance significativo para su programa de armamento nuclear y que prorrogar la suspensión de las sanciones conforme al PAIC resultaba vital para los intereses de Estados Unidos y era «apropiado y proporcionado» a las medidas adoptadas por Irán para poner fin a su programa de armas nucleares. En caso de que el Presidente optara por no emitir las certificaciones previstas, el Congreso quedaba habilitado para introducir de nuevo las sanciones suspendidas haciendo uso de un procedimiento abreviado.

49 Tras denunciar el efecto desestabilizador de la actuación de Irán en diferentes ámbitos, el Presidente Trump concluyó que no podía certificar que la suspensión de las sanciones era «apropiada y proporcionada» a las medidas aplicadas por Irán para terminar su programa de armamento nuclear (White House, Remarks by President Trump on Iran Strategy, 13 de octubre de 2017, disponible en https://www.whitehouse.gov/briefings-statements/remarks-president-trump-iranstrategy/). El Congreso, sin embargo, no hizo uso de la facultad que le confería la Ley sobre el acuerdo nuclear para poner en marcha de nuevo las sanciones. De este modo, la decisión última respecto a las sanciones se le dejaba al Presidente (en este sentido, vid. «President Trumps Withdraws the United States from the Iran Deal and Announces the Reimposition of Sanctions», AfIL, vol. 112, n. 3, pp. 514-522, nota 8).

50 Mulligan, S.P., Withdrawal from International Agreements: Legal Framework, the Paris Agreement, and the Iran Nuclear Agreement, Congressional Research Service Report R44761, Library of Congress, Washington D.C., 4 mayo 2018, p. 20; Katzman, K.; KerR, P. K.; Heitshusen, V., Options to Cease Implementing the Iran Nuclear Agreement Congressional Research Service Report R44942, Library of Congress, Washington D.C, 5 de abril, 2018, p. 2. 
del PAIC por parte de Irán. Pese a no emitir la certificación, Trump prorrogó de nuevo el levantamiento de las sanciones aunque en esta ocasión anunció su intención de retirarse del PAIC inmediatamente si el acuerdo no era renegociado para corregir sus «graves defectos» ${ }^{51}$.

Las iniciativas diplomáticas no lograron desembocar en un acuerdo complementario $^{52}$. Finalmente, el 8 de mayo de 2018, el Presidente anunció la retirada de Estados Unidos del PAIC y ordenó la reimposición de las sanciones que habían sido levantadas en aplicación del mismo ${ }^{53}$. El Memorando

51 Uno de los elementos del acuerdo más criticado era la previsión de «cláusulas de terminación» (sunset clauses), que ponían fin a las restricciones de las actividades nucleares iraníes tras un periodo de 10 o 15 años según los casos. Otro aspecto era que el acuerdo no incluyera medidas para impedir el desarrollo de misiles balísticos intercontinentales por parte de Irán. Junto a estos aspectos concretos, el PAIC se consideraba viciado en origen, por lo restringido de su enfoque, limitado al desarrollo del programa nuclear de Irán (y dentro de ciertos límites) y prescindiendo de otras actividades desestabilizadoras de Irán. El Presidente formuló las condiciones para seguir en el PAIC: «my Administration has engaged with key European allies in seeking to secure a new supplemental agreement that would impose new multilateral sanctions if Iran develops or tests long-range missiles, thwarts inspections, or makes progress toward a nuclear weapon-requirements that should have been in the nuclear deal in the first place. And, [...], these provisions of a supplemental agreement must never expire. [...] Today, I am waiving the application of certain nuclear sanctions, but only in order to secure our European allies' agreement to fix the terrible flaws of the Iran nuclear deal. This is a last chance. In the absence of such an agreement, the United States will not again waive sanctions in order to stay in the Iran nuclear deal». (White House, Statement by the President on the Iran Nuclear Deal, 12 de enero de 2018, disponible en https://www.whitehouse.gov/briefings-statements/ statement-president-iran-nuclear-deal/).

52 Durante los meses de febrero, marzo y abril se sucedieron contactos diplomáticos a diferente nivel entre Estados Unidos y los miembros del E3, Reino Unido, Francia y Alemania. Según lo recogido en los comunicados de prensa, las conversaciones se habían centrado esencialmente en las «cláusulas de terminación», en el desarrollo de misiles balísticos intercontinentales y en el reforzamiento del sistema de inspección. Para mayor detalle, vid. «President Trumps Withdraws the United States...», op. cit., p. 516. En un intento de preservar la integridad del acuerdo, un grupo formado por quinientos miembros de los parlamentos del Reino Unido, Francia y Alemania dirigió una carta abierta a los miembros del congreso estadounidense solicitando que trataran de persuadir al Presidente Trump de permanecer en el PAIC (véase 500 French, British and German MPs write to their US counterparts to support the $7 C P O A$, disponible en https://europeanmpsforjcpoa.com)

53 En su declaración Trump criticaba de nuevo algunos aspectos del acuerdo y comunicaba la decisión de imponer de nuevo las sanciones en vigor antes de la aplicación del PAIC: «The agreement was so poorly negotiated that even if Iran fully complies, the regime can still be on the verge of a nuclear breakout in just a short period of time. The deal's sunset provisions are totally unacceptable... the deal's inspection provisions lack adequate mechanisms to prevent, detect, and punish cheating, and don't even have the unqualified right to inspect many important locations, including military facilities... [A] comprehensive, and lasting solution to the Iranian nuclear threat... will include efforts to eliminate the threat of Iran's ballistic missile program; 
presidencial adoptado al efecto proporcionaba directrices específicas para que todas las sanciones volvieran a ser efectivas en el plazo de 6 meses $^{54}$. El memorando estableció dos categorías de sanciones previendo plazos diferentes para cada una:

«we're providing a six-month wind down for energy-related sanctions. So that's oil, petroleum, petrochemicals, and then all of the ancillary sanctions that are associated with that... Everything else is going to have a 90-day wind down... [T] he architecture of the Iranian sanctions program was quite complex, but everything else includes things like dealing in the trial, providing metal - precious metals and gold to the Iranian regime, providing U.S. banknotes.» ${ }^{55}$

Transcurridos los seis meses señalados, el régimen de sanciones debía responder a la misma estructura que había tenido antes de la aplicación del PAIC. Las sanciones secundarias contra entidades e individuos no estadounidenses, por lo tanto, recobrarían su vigencia.

La reacción internacional a la notificación de retirada del PAIC fue inmediata. El 8 de mayo, la Unión Europea, por medio de la Alta Representante F. Mogherini, lamentó la decisión estadounidense y reafirmó el compromiso europeo con la aplicación del acuerdo ${ }^{56}$. Los Estados adoptaron, en su mayoría, una postura de pesar unida a cierto criticismo o incluso protesta en el caso de

to stop its terrorist activities worldwide; and to block its menacing activity across the Middle East. In the meantime, powerful sanctions will go into full effect» (White House, Remarks by President Trump on the Foint Comprehensive Plan of Action, 8 de mayo de 2018, disponible en https://www.whitehouse.gov/briefings-statements/remarks-president-trump-joint-comprehensive-plan-action/).

54 White House, News, Presidential Memorandum, Ceasing U.S. Participation in the FCPOA and Taking Additional Action to Counter Iran's Malign Influence and Deny Iran All Patbs to a Nuclear Weapon, 8 de mayo de 2018, disponible en https://www.whitehouse.gov/presidential-actions/ ceasing-u-s-participation-jcpoa-taking-additional-action-counter-irans-malign-influence-deny-iran-paths-nuclear-weapon/

55 United States Department of State, Background Briefing on President Trump's Decision To Withdraw From the 7CPOA, 8 de mayo, 2018. Junto a estas medidas, había que proceder a incluir de nuevo en la lista de individuos y entidades alrededor de cuatrocientas personas, por motivos derivados de su propia actuación, y otras doscientas, identificadas como parte del gobierno de Irán, un proceso complejo para el que también se fijaba el plazo de seis meses (ibid.).

56 Unión Europea, Servicio Europeo de Acción Exterior (SEAE), Remarks by High Representative/ Vice-President Federica Mogherini on the statement by US President Trump regarding the Iran nuclear deal (7CPOA), 8 de mayo, 2018. 
Irán. Israel y Arabia Saudí manifestaron su apoyo a la decisión de Estados Uni$\operatorname{dos}^{57}$. Los miembros del E3 (Reino Unido, Francia y Alemania), emitieron un comunicado conjunto para reafirmar su pleno compromiso con la aplicación del acuerdo en la nueva situación:

«It is with regret and concern that we, the Leaders of France, Germany and the United Kingdom take note of President Trump's decision to withdraw the United States of America from the Joint Comprehensive Plan of Action.

Together, we emphasize our continuing commitment to the JCPoA. This agreement remains important for our shared security. We recall that the JCPoA was unanimously endorsed by the UN Security Council in resolution 2231. This resolution remains the binding international legal framework for the resolution of the dispute about the Iranian nuclear programme. We urge all sides to remain committed to its full implementation and to act in a spirit of responsibility. ${ }^{58}$

En una reunión a nivel ministerial celebrada el 24 de septiembre de 2018, los participantes en el PAIC analizaron posibles vías para afrontar los problemas derivados de la retirada y consiguiente reimposición de sanciones por parte de Estados Unidos. La Unión Europea ya había recuperado, modificándola, normativa anterior para contrarrestar los efectos de la aplicación extraterritorial de las sanciones estadounidenses ${ }^{59}$. Para mantener vivo el acuerdo,

57 En este sentido, véase «President Trumps Withdraws...», op. cit., pp. 519-520.

58 United Kingdom, Prime Ministers Office, Press Release, foint statement from Prime Minister Theresa May, Chancellor Angela Merkel and President Emmanuel Macron following President Trump's statement on Iran, 8 de mayo de 2018, disponible en https://www.gov.uk/government/ news/joint-statement-from-prime-minister-may-chancellor-merkel-and-president-macronfollowing-president-trumps-statement-on-iran. El comunicado hace referencia a una cuestión ampliamente debatida a nivel doctrinal y por parte de la propia Administración estadounidense: la existencia o no de una obligación jurídica de cumplir el Plan de Acción Resolución en virtud de la resolución 2231(2015). El tema es abordado en una sección posterior de este trabajo.

59 En 1996 la Comunidad Europea adoptó el Reglamento (CE) n. ${ }^{\circ} 2271 / 96$ del Consejo, de 22 de noviembre de 1996, para proteger los intereses de personas físicas y entidades en la Unión Europea que participaban en actividades de comercio internacional susceptibles de resultar afectadas por la aplicación extraterritorial de legislación de terceros estados enumerada en el anexo. El anexo recogía las diferentes normas de Estados Unidos mediante las que se había impuesto sanciones económicas a Cuba, Libia e Irán. El reglamento (EU) 2018/1100, de 6 de junio, sustituyó el anexo del anterior por un nuevo anexo que incluía las medidas adoptadas por Estados Unidos 
no obstante, era necesario poner en marcha un mecanismo especial (Special Purpose Vebicle) susceptible de garantizar la existencia de cauces de pago con Irán efectivos, si bien no se ha proporcionado información específica sobre el mismo $^{60}$.

Aunque todos los informes emitidos hasta el momento por el OIEA habían afirmado que Irán había cumplido los compromisos asumidos en el marco del acuerdo ${ }^{61}$, el Presidente Trump había acusado a Irán de comportamiento contrarios al PAIC en varias ocasiones ${ }^{62}$. Teniendo en cuenta que los informes del OIEA cubren sólo los compromisos específicos de las Partes sujetos a los poderes de verificación del Organismo, la aparente divergencia no refleja necesariamente una contradicción. También algunos informes de Naciones Unidas sobre el cumplimiento de la resolución 2231 (2015) se hacían eco de que los lanzamientos realizados por Irán para probar misiles han sido considerados por algunos Estados miembros del Consejo contrarios a la resolución 2231(2015). Otros informes sobre determinadas crisis regionales, ponían igualmente de manifiesto aparentes violaciones por Irán de las restricciones a la exportación de armas establecidas en la resolución 2231 $(2015)^{63}$.

tras la retirada del PAIC. El reglamento hace constar la convicción de que las medidas adoptadas por terceros Estados, y las acciones en ellas basadas, cuando su aplicación afecta «a los intereses de las personas físicas y jurídicas en la Unión que se dediquen al comercio internacional y/o al movimiento de capitales y a actividades comerciales afines entre la Unión y terceros países» violan el derecho internacional por su carácter extraterritorial.

60 Unión Europea, SEAE, Implementation of the Foint Comprehensive Plan of Action: Foint Ministerial Statement of the E3/EU+2 (China, Francia, Alemania, Federación rusa, Reino Unido, Unión Europea e Irán), Nueva York, 24 de septiembre, 2018, disponible en https://eeas.europa.eu/ headquarters/headquarters-homepage/51036/implementation-joint-comprehensive-plan-action-joint-ministerial-statement.

61 También el último informe del Director General de la OIEA, de noviembre de 2018, se pronuncia en este sentido: «El Organismo sigue verificando la no desviación de los materiales nucleares declarados en las instalaciones nucleares y lugares situados fuera de las instalaciones en los que se utilizan habitualmente materiales nucleares (LFI) declarados por el Irán en virtud de su Acuerdo de Salvaguardias. Se siguieron realizando respecto del Irán evaluaciones relativas a la ausencia de materiales y actividades nucleares no declarados» (Verificación y vigilancia en la República Islámica del Irán a la luz de la resolución 2231 (2015) del Consejo de Seguridad de las Naciones Unidas, GOV/2018/47, 13 de noviembre de 2018, par. 26).

$62 V i d$., entre otros, su discurso relativo a la estrategia sobre Irán: Remarks by President Trump on Iran Strategy (13 de octubre de 2017), https://www.whitehouse.gov/the-press-office/2017/10/13/ remarks-president-trump-iran-strategy.

63 Katzman, K., Iran Sanctions..., op. cit., p. 40. 


\section{III.2. Valoración jurídica de la retirada del acuerdo desde la perspectiva del derecho de Estados Unidos}

El procedimiento jurídico para desvincular a Estados Unidos de tratados y otros acuerdos internacionales ha generado un largo debate entre el ejecutivo y el legislativo de dicho país. La Constitución de Estados Unidos, al igual que otras, regula el procedimiento para la adopción de acuerdos internacionales pero guarda silencio acerca del mecanismo para su terminación. Para la conclusión de determinadas categorías de acuerdos (para los que reserva el término Tratado) la Constitución estadounidense exige el consentimiento de Senado. El Ejecutivo puede también adoptar acuerdos internacionales contando con la aprobación por mayoría simple de ambas Cámaras (Congressional-Executive Agreements) o sin participación alguna del Congreso, en el caso de los Acuerdos presidenciales (también denominados Sole Executive Agreements) ${ }^{64}$. La cuestión puede revestir mayor complejidad cuando el Congreso ha adoptado medidas legislativas para la aplicación del Tratado en el orden interno. Algunos autores han señalado que el procedimiento para retirarse de un acuerdo dependería de su naturaleza, pudiendo requerir en algunos casos la implicación del Congreso o del Senado. No existe una respuesta pacíficamente aceptada sobre los términos para resolver el eventual conflicto de poderes ${ }^{65}$. De acuerdo con la postura que prevalece en la práctica, el Presidente está facultado para retirar a Estados Unidos de los tratados sin necesidad de obtener la aprobación del Senado, cuando la retirada está permitida por el Derecho Internacional ${ }^{66}$.

Si se acepta que, efectivamente, el PAIC es un compromiso político no vinculante y no un tratado internacional, la decisión de Trump de retirarse

64 La Constitución de Estados Unidos reserva el término «tratado» para los acuerdos internacionales aprobados por una mayoría de dos tercios del Senado y ratificados por el Presidente. Véase una explicación sintética y clara sobre las diferentes categorías de acuerdos en KIRGIS, F. L., «International Agreements and U.S. Law», ASIL Insights, vol. 2, n. 5, 1997, disponible en https:// www.asil.org/insights/volume/2/issue/5/international-agreements-and-us-law.

65 Para un análisis breve de casos y jurisprudencia al respecto, Mulligan, S.P., Withdrawal from International Agreements: Legal Framework, the Paris Agreement, and the Iran Nuclear Agreement, Congressional Research Service Report R44761, Library of Congress, Washington D.C., 4 mayo 2018, pp. 6-17.

66 «Trump Administration Announces Withdrawal from Four International Agreements», AfIL, vol. 113, n. 1, 2019, p. 133. Una proposición del American Law Institute señala al respecto: «[a] ccording to established practice, the President has the authority to act on behalf of the United States in... whithdrawing the United States from treaties, either on the basis of terms in the treaty (such as a withdrawal clause) or on the basis of international law that would justify such action» (American Law Institute's Restatement Fourth of Foreign Relations Law of the United States, $\$ 313$, allí citado en n. 21). 
del acuerdo y de reimponer las sanciones suspendidas en virtud del mismo no sería contraria al Derecho internacional, sin perjuicio de las consecuencias políticas de diferente índole que podría suscitar ${ }^{67}$. Como destaca uno de los pronunciamientos del American Law Institute, puede existir un poderoso incentivo para cumplir los acuerdos políticos, porque pueden estar dotados de tal fuerza moral o política, o conllevar tales beneficios, que su incumplimiento comporte consecuencias graves ${ }^{68}$.

El Presidente Obama, al llegar el Día de aplicación, había revocado órdenes ejecutivas anteriores que establecían sanciones secundarias sobre Irán. Esta facultad entra dentro de las competencias generalmente reconocidas al Presidente de Estados Unidos ${ }^{69}$. Por consiguiente, el Presidente Trump podría restablecer las sanciones así levantadas mediante la adopción de una nueva orden ejecutiva, adoptada de conformidad con la ley de base respectiva que faculta al Presidente para sancionar a Irán mediante órdenes ejecutivas ${ }^{70}$. En el caso de sanciones impuestas mediante leyes, éstas suelen conferir al Presidente la facultad de suspender las sanciones cuando se reúnen determinadas condiciones y durante un periodo de tiempo especificado, transcurrido el cual la suspensión debe ser renovada. Durante el mandato de Obama la Administración hizo uso de esta prerrogativa para cumplir el PAIC y el presidente Trump renovó estas suspensiones de las sanciones en dos ocasiones, el 17 de julio de 2017 y el 12 de enero de 2018. Por consiguiente, las sanciones impuestas mediante ley recobrarían su vigencia una vez expirado el periodo de vigencia de la suspensión en caso de que el Presidente Trump no adoptara una nueva decisión para renovarla ${ }^{71}$.

En definitiva, la conclusión mayoritaria estima que desde la perspectiva del derecho interno estadunidense no existían obstáculos jurídicos para que el Presidente adoptara la decisión de retirar a Estados Unidos del PAIC ${ }^{72}$.

67 Mulligan, S.P., Withdrawal from International Agreements..., op. cit., p. 24.

68 American Law Institute's Restatement Third of Foreign Relations Law of the United States, $\$ 303(1)$, 1987. Las proposiciones enunciadas por el American Law Institute aunque no vinculantes son un punto de referencia que goza de particular autoridad en el ámbito jurídico estadounidense (Mulligan, S.P., Withdrawal from International Agreements..., op. cit., p. 1, nota 8).

69 Mulligan, S.P., Withdrawal from International Agreements..., op. cit., p. 25.

70 Para un análisis detallado de las leyes existentes en este ámbito, vid. RENNACK, D. E, Iran: U.S. Economic Sanctions and the Authority to Lift Restrictions, Congressional Research Service Report R43311, Library of Congress, Washington D.C., 10 mayo 2018, disponible https://fas.org/ sgp/crs/mideast/R43311 [consultado: 07/01/2018].

71 Mulligan, S.P., Withdrawal from International Agreements..., op. cit., p. 23.

72 Ibid., p. 26. 


\section{III.3. La retirada del PAIC por Estados Unidos desde la perspectiva del Derecho Internacional: alcance de la resolución 2231 (2015)}

Dilucidar si una resolución establece obligaciones jurídicas para sus destinatarios exige prestar atención a los términos empleados. La resolución 2231 introduce la parte dispositiva «recalcando que los Estados Miembros están obligados en virtud del Artículo 25 de la Carta de las Naciones Unidas a aceptar y cumplir sus decisiones ${ }^{73}$. A continuación, tras «hacer suyo» (endorse) el Plan de Acción $^{74}$, el Consejo de Seguridad formulaba el comportamiento a seguir respecto al acuerdo en los siguientes términos:

«Exhorta (calls upon) a todos los Estados Miembros, las organizaciones regionales y las organizaciones internacionales a que adopten las medidas oportunas para apoyar la aplicación del PAIC, incluso tomando medidas acordes con el plan de aplicación expuesto en el PAIC y en la presente resolución y absteniéndose de realizar acciones que menoscaben el cumplimiento de los compromisos asumidos en el PAIC. $\gg^{75}$

Algunos autores han defendido la tesis de que la incorporación del PAIC en el Anexo A de la resolución 2231 del Consejo de Seguridad, había tenido el efecto de dotar a algunas de sus disposiciones de carácter obligatorio. La referencia expresa al artículo 25 de la Carta y la invocación del artículo 41 en algunas disposiciones de la resolución constituyen los ejes centrales de esta argumentación ${ }^{76}$.

Algunos autores, por el contrario, han sostenido que la resolución 2231 (2015) aprueba el Plan de Acción con un lenguaje exhortativo que no modifica su carácter no vinculante ${ }^{77}$. Desde esta perspectiva, se destaca que la expresión

\footnotetext{
S/RES/2231(2015), p. 3.

S/RES/2231(2015), par. 1.

S/RES/2231(2015), par. 2

Afrasiabi, K. L., «Trump and the Iran Nuclear Accord: The Legal Hurdles», Columbia/SIPA Fournal of International Affairs, febrero 2018disponible en https://jia.sipa.columbia.edu/online-articles/trump-and-iran-nuclear-accord-legal-hurdles. Para bibliografía adicional en este sentido, véase «President Trumps Withdraws...», op. cit., nota 37; Mulligan, S.P., Withdrawal from International Agreements..., op. cit., nota 187.

77 JoYner, D., «The Trump Presidency and the Iran Nuclear Deal: Initial Thoughts», 17 noviembre 2016, disponible en ejiltalk.org/the-trump-presidency-and-the-iran-nuclear-deal-initialthoughts/. Una sintética recopilación de autores que se han pronunciado en este sentido es ofrecida en el trabajo de Mulligan, S.P., Withdrawal from International Agreements..., op. cit., nota 199 .
} 
calls upon es utilizada mayoritariamente por el Consejo con un valor meramente recomendatorio ${ }^{78}$.

Un razonamiento similar, «que las resoluciones relevantes del Consejo no estaban formuladas con un lenguaje vinculante sino exhortativo y que por lo tanto no pretendían imponer ninguna obligación jurídica ni afectar jurídicamente al derecho de ningún Estado ${ }^{79}$ fue rechazado por la Corte Internacional de Justicia en la opinión consultiva sobre el asunto de Namibia. Se trataba de una argumentación excesivamente genérica para resultar concluyente. A juicio de la Corte, la determinación de la naturaleza vinculante o no de una resolución, requiere un cuidadoso análisis de sus términos, «de los debates que han conducido a su adopción, de las disposiciones de la Carta invocadas $y$, en general, de todas las circunstancias que pudieran ayudar a determinar las consecuencias jurídicas» ${ }^{80}$ de la resolución. En esa opinión consultiva, considerando el contenido de la resolución en su conjunto y el tipo de actuación llevado a cabo por el Consejo de Seguridad, la Corte llegó a la conclusión de que una de las disposiciones controvertidas de la resolución 276 (1970), introducida con la expresión calls upon, tenía valor obligatorio ${ }^{81}$.

El hecho de que la resolución 2231 (2015) invoque el artículo 25 de la Carta tampoco determina por sí solo su valor vinculante. Como subraya la opinión consultiva sobre el asunto Namibia, es necesario analizar en cada caso si el Consejo ha ejercido de hecho las facultades conferidas por el artículo 25. El conjunto de circunstancias llevó a la Corte a concluir en ese supuesto que las disposiciones controvertidas en cuanto a su alcance tenían efectos vinculantes, a pesar de su formulación no impositiva.

Las circunstancias del presente caso, sin embargo, no parecen conducir a la misma conclusión. La adopción de la resolución 2231 (2015) era una condición necesaria para que los participantes en el PAIC pudieran reanudar determinadas actividades económicas con Irán sin vulnerar las resoluciones vinculantes del Consejo de Seguridad a las que la resolución 2231 pone fin. No tiene como finalidad imponer un régimen obligatorio, sino más bien re-

78 Una breve selección de análisis en este sentido es ofrecida en el trabajo de MuLLiGan, S.P., Withdrawal from International Agreements..., op. cit., nota 199.

79 Legal Consequences for States of the Continued Presence of South Africa in Namibia (South West Africa) notwithstanding Security Council Resolution 276 (1970), Advisory Opinion, I.C.F. Reports 1971, p. 53, par. 114.

80 I.C.7. Reports 1971, p. 53, par. 114.

81 I.C.F. Reports 1971, p. 53, par. 115. 
tirar los obstáculos jurídicos para la aplicación de un acuerdo particular ${ }^{82}$. El Consejo de Seguridad, se ha señalado, podría ser considerado un participante más en el PAIC, cuyo compromiso era requisito imprescindible para alcanzar el acuerdo ${ }^{83}$. En el presente caso, resulta difícil interpretar que la exhortación dirigida a los Estados por la resolución tiene por efecto crear para los mismos una obligación.

Las declaraciones de miembros del Consejo tras la adopción de la resolución no resultan concluyentes en cuanto al valor que el refrendo del Consejo de Seguridad confiere a los compromisos del acuerdo. El tono generalmente desleído de las intervenciones favorece la impresión de que se trata de una resolución débil, aunque contenga algunas disposiciones vinculantes.

La representante de Estados Unidos enfatizó el éxito diplomático que representaba la adopción del PAIC tras más de una década de sanciones y después de dos años de arduas negociaciones. Su intervención se centró en el contenido del Plan de Acción, subrayando los beneficios que comportaría la aplicación del acuerdo e insistiendo en la importancia esencial que revestía, a partir de ese momento, el compromiso de todas las partes con su cumplimiento efectivo. De la resolución 2231 (2015) únicamente se dice que «consagra» el PAIC ${ }^{84}$. Del tenor general de su intervención parece desprenderse que la resolución, aparte del levantamiento de las sanciones, no afecta al panorama jurídico: el acuerdo sigue descansando en el cumplimiento voluntario de las partes, el incumplimiento de Irán comportaría la reanudación de las sanciones y el PAIC acentúa el compromiso de los participantes con las obligaciones derivadas del TNP y otras normas internacionales pertinentes $^{85}$.

El representante de China subrayó el carácter político de la solución plasmada en el Acuerdo y valoró la adopción de la resolución 2231 como una

82 La resolución indica que el PAIC está llamado a aplicarse exclusivamente entre los participantes en el mismo, y que en ningún caso debe interpretarse que sus disposiciones afectan a los derechos y obligaciones establecidos en el TNP ni demás acuerdos pertinentes (S/RES/2231(2015), par. 27).

83 JOYNER, D., Iran's Nuclear Program..., op. cit., p. 242.

84 Entre otros aspectos, se argumenta que la aplicación del PAIC, con la puesta en marcha de un riguroso sistema de inspección y verificación supervisado por el OIEA, impediría a Irán obtener material fisionable destinado a la fabricación de un arma nuclear. En otro momento, se señala que la aplicación del acuerdo tendría el efecto de cuadriplicar el actual «tiempo de producción» de Irán, es decir el tiempo necesario para producir la dosis necesaria del uranio adecuado para la fabricación de un arma nuclear (S/PV.7488, p. 2).

85 S/PV.7488, pp. 2-4. 
medida importante para la aplicación del mismo ${ }^{86}$. Para el representante ruso, el respaldo del Plan de Acción por medio de la resolución 2231 (2015) constituía un giro fundamental en el enfoque hasta entonces mantenido por el Consejo respecto el programa nuclear iraní, una opción por los medios políticos y diplomáticos, conforme al derecho internacional en general y al TNP, en particular $^{87}$. La aprobación de la resolución, para Reino Unido, representaba la culminación de las negociaciones desarrolladas durante más de un decenio, el punto de referencia para reconsiderar la relación con Irán y la oportunidad para restablecer relaciones económicas con Irán ${ }^{88}$.

Resulta interesante la observación de la representante de Lituania acerca de la diferente naturaleza de los compromisos asumidos en virtud del PAIC aprobado por la resolución, y de «las obligaciones jurídicamente vinculantes basadas en la Carta de cumplir el embargo de armas y abstenerse de actividades relacionadas con los misiles balísticos» ${ }^{89}$. Únicamente el presidente del Consejo, pronunciándose en calidad de representante de Nueva Zelanda, expresó el parecer de que la aprobación de la resolución 2231 (2015) otorgaba «fuerza jurídica internacional» al PAIC $^{90}$.

En atención a las consideraciones expuestas, cabe distinguir una doble vertiente en la resolución 2231. La primera comprende las disposiciones referidas a la terminación (y eventual reanudación) de las resoluciones 1696 (2006), 1737 (2006), 1747 (2007), 1803 (2008), 1835 (2008), 1929 (2010) y 2224 (2015). Se trata de las resoluciones mediante las que el Consejo había adoptado sanciones relativas el desarrollo del programa nuclear de Irán. El alcance jurídico de la resolución en este ámbito es claro: el Consejo se sitúa expresamente en el marco del artículo 41 para poner fin a las resoluciones anteriores adoptadas sobre la base del mismo artículo.

En realidad no se trata de una derogación absoluta. El Consejo de Seguridad aprobó un mecanismo, también actuando en el marco del artículo 41 de la Carta, mediante el cual si un Estado parte en el PAIC notificaba al Consejo

86 Naciones Unidas, Documentos Oficiales del Consejo de Seguridad, S/PV.7488, 7488 sesión, 10 de julio de 2015 , p. 5 .

87 S/PV.7488, p. 6. A juicio del representante ruso, la resolución confirma «el derecho inalienable de Irán a desarrollar un programa nuclear pacífico», al mismo tiempo que garantiza la supervisión del Organismo OIEA.

88 S/PV.7488, p. 7.

89 Naciones Unidas, Documentos Oficiales del Consejo de Seguridad, S/PV.7488, 7488 sesión, 10 de julio de 2015, p. 11.

90 S/PV.7488, p. 13. 
un incumplimiento significativo del Plan de Acción, el Consejo debía aprobar otra resolución para que la terminación de las sanciones siguiera en vigor ${ }^{91}$. Si transcurrido el plazo de treinta días establecido a tal efecto el Consejo no hubiera aprobado una resolución en este sentido, recobrarían su vigencia todas las disposiciones de las resoluciones 1696 (2006), 1737 (2006), 1747 (2007), 1803 (2008), 1835 (2008) y 1929 (2010) cuya terminación había decidido el párrafo 7 de la resolución ${ }^{92}$. Este mecanismo, denominado snapback, tiene el efecto de invertir el modo en que normalmente operaría el derecho de veto. Su inclusión garantizaba que ni China ni Rusia, que habían frenado acciones del Consejo contra Irán en ocasiones anteriores, pudieran impedir la reanudación de las sanciones en caso de incumplimiento del acuerdo por Irán ${ }^{93}$. Se ha señalado, a este respecto, que el mecanismo del snapback, impone al Consejo la carga del voto afirmativo para mantener la derogación de las sanciones: el veto de cualquier miembro permanente a la nueva resolución permitiría restaurar las sanciones ${ }^{94}$. En definitiva, serían inequívocamente vinculantes, aquellas provisiones de la resolución en la que el Consejo «decide, actuando en virtud del artículo 41» la terminación de sus resoluciones previas sobre el programa nuclear de Irán, procediendo a un levantamiento de las sanciones que primero es parcial, sujeto a límites y cautelas durante las etapas señaladas en la resolución ${ }^{95}$ y total, transcurridos 10 años desde el «día de la aprobación»

91 El texto en inglés de la resolución 2231 (2015) dispone que el Consejo de Seguridad: «Decides, acting under Article 41 of the Charter of the United Nations, that, within 30 days of receiving a notification by a JCPOA participant State of an issue that the JCPOA participant State believes constitutes significant non-performance of commitments under the JCPOA, it shall vote on a draft resolution to continue in effect the terminations in paragraph 7 (a) of this resolution» (par. 11). El texto español de la resolución en este punto es particularmente desafortunado («[el Consejo de Seguridad] someterá a votación un proyecto de resolución para que continúen en vigor las disposiciones cuya terminación se establece en el párrafo 7 a) de la presente resolución»), significa lo contrario del fin perseguido por la resolución.

92 Conforme al párrafo 12 de la Resolución «if the Security Council does not adopt a resolution under paragraph 11 to continue in effect the terminations in paragraph 7 (a), then effective midnight Greenwich Mean Time after the thirtieth day after the notification to the Security Council described in paragraph 11, all of the provisions of resolutions 1696 (2006), 1737 (2006), 1747 (2007), 1803 (2008), 1835 (2008), and 1929 (2010) that have been terminated pursuant to paragraph 7 (a) shall apply in the same manner as they applied before the adoption of this resolution.»

93 LAUB, Z., «International Sanctions on Iran», op. cit., p. 6.

94 Vid., Mulligan, S. P., Withdrawal from International Agreements..., op. cit., p. 31.

95 S/RES/2231(2015), par. 7, 21-23. Aunque el párrafo 7.a) parece estar operando un levantamiento total de las sanciones, la letra b) remite a una serie de disposiciones del Anexo b), que 
del PAIC $^{96}$. Naturaleza obligatoria tendrían igualmente las disposiciones relativas el mecanismo para restaurar las sanciones en caso de notificación de incumplimiento del PAIC por un Estado parte (snapback) ${ }^{97}$.

La segunda vertiente de la resolución comprende las disposiciones específicamente dirigidas a los Estados partes en el PAIC y las relativas al resto de Estados. Aquí resulta más complicado determinar si la resolución 2231 (2015) ha tenido el efecto de transformar los compromisos voluntarios de los participantes conforme al PAIC, en obligaciones vinculantes. Del lenguaje utilizado por la resolución y del conjunto de circunstancias expuesto, se desprende que la aprobación de la resolución 2231 (2015) por el Consejo de Seguridad no transforma la naturaleza jurídica del Plan de Acción, que sigue constituyendo un acuerdo no vinculante. El conjunto de disposiciones incluidas en esta vertiente o bien están enunciadas en términos indiscutiblemente recomendatorios $^{98}$, o bien han sido formuladas en términos deliberadamente ambiguos ${ }^{99}$. En este segundo supuesto, ni la resolución en su conjunto ni las demás circunstancias concurrentes parecen apoyar su valor vinculante.

El párrafo 7 de la resolución 2231(2015) resulta particularmente ilustrativo de esta doble vertiente, y también de hasta qué punto la ambigua redacción del texto puede complicar la tarea de la interpretación. En virtud del mismo, el Consejo de Seguridad:

«Decide, actuando en virtud del Artículo 41 de la Carta de las Naciones Unidas, que, una vez reciba el informe del OIEA descrito en el párrafo 5:

a) Se terminará la aplicación de las disposiciones de las resoluciones 1696 (2006), 1737 (2006), 1747 (2007), 1803 (2008), 1835 (2008), 1929 (2010) у 2224 (2015);

restringen el alcance de la derogación de las sanciones durante un periodo de tiempo de 5 o de 8 años según los casos.

96 S/RES/2231(2015), par. 8. En virtud de este párrafo, el Consejo de Seguridad: «Decide, actuando en virtud del Artículo 41 de la Carta de las Naciones Unidas, que en la fecha en que se cumplan 10 años desde el Día de Aprobación del PAIC, tal como se define en el PAIC, se terminará la aplicación de todas las disposiciones de la presente resolución, y ninguna de las resoluciones anteriores mencionadas en el párrafo 7 a) será aplicable, habrá concluido su examen de la cuestión nuclear iraní, y el tema titulado «No proliferación» se eliminará de la lista de asuntos que se hallan sometidos al Consejo».

97 S/RES/2231(2015), par. 10-12.

98 Entre otros, par. 10 (alienta); algunas cláusulas del par. 13 (pone de relieve, observa); par. 15 (afirma, alienta) par. 17 (solicita, invita, alienta), etc.

99 El término decide, por ejemplo, es usado en varias ocasiones sin la cláusula «actuando en virtud del Artículo 41 de la Carta de las Naciones Unidas», por ejemplo, en par. 25 y 27). 
b) Todos los Estados deberán cumplir lo dispuesto en los párrafos 1, 2, 4 y 5 y en los subpárrafos a) a f) del párrafo 6 del anexo $\mathrm{B}$ durante el período especificado en cada párrafo o subpárrafo, y son exhortados a cumplir lo dispuesto en los párrafos 3 y 7 del anexo $\mathrm{B}$ »

La cláusula del apartado a) no ofrece dudas en cuanto a su alcance jurídico vinculante: tiene el efecto de levantar las sanciones establecidas en las resoluciones que cita.

La cláusula del apartado b), aunque también responde a una decisión del Consejo en virtud del artículo 41», comprende dos enunciados de diferente valor. En virtud del primero, el Consejo decide que todos los Estados «deberán cumplir» determinadas disposiciones del Anexo B de la resolución. La mayoría de estas disposiciones autorizan determinadas actividades comerciales con Irán tras el levantamiento de las sanciones sujetándolas a restricciones de diferente tipo, como la necesidad de obtener la autorización del Consejo de Seguridad, por ejemplo. Este aspecto, la necesidad de respetar las restricciones, también tendría valor obligatorio. En virtud del segundo enunciado, por el contrario, los Estados «son exhortados» a cumplir otras dos disposiciones del Anexo B. El cambio de lenguaje resulta significativo: no tendría sentido utilizar un término diferente, usualmente recomendatorio, si se quería conferir el mismo efecto jurídico a dos proposiciones que se encontraban en el mismo párrafo. No parece, por tanto, que se haya querido dotar a la segunda parte del párrafo 7.b de valor vinculante ${ }^{100}$.

${ }^{100}$ Es la conclusión que mejor responde también al contenido del párrafo 7, del Anexo B. El alcance del párrafo 3 es extremadamente intrincado. Hace referencia a las actividades iraníes en materia de misiles balísticos. La resolución 1929 (2010), de 9 de junio, imponía a Irán la prohibición de desarrollar cualquier actividad con misiles balísticos capaces de transportar armas nucleares ( $\ll$ Decides that Iran shall not undertake any activity related to ballistic missiles capable of delivering nuclear weapons), y a los demás Estados la obligación de evitar la transferencia de tecnología relacionada con estas actividades, vid. S/RES/1929 (2010), par. 9. El PAIC guarda silencio sobre el programa de misiles balístico de Irán. La resolución 2231 (2015), sí incluyó la cuestión pero estableciendo un régimen menos restrictivo. El lenguaje prescriptivo de la resolución 1929 (2010) es sustituido por términos exhortativos («se exhorta al Irán a que no emprenda ninguna actividad relacionada con los misiles balísticos diseñados para poder ser vectores de armas nucleares») y por duración limitada (hasta que transcurran 8 años desde el Día de aprobación del PAIC»). Vid. S/RES/2231(2015), Anexo B, par. 3). D. Joyner califica el texto de la resolución como una victoria para Irán. Durante las negociaciones del PAIC, Irán había rechazado incluir el programa de misiles balísticos dentro del acuerdo y alegado de modo persistente que las restricciones del Consejo de Seguridad eran injustificadas (JOYNER, D., Iran's Nuclear Program and International Law..., op. cit., pp. 141-142). 
A la luz de estas consideraciones, Estados Unidos hubiera podido invocar el mecanismo del snapback establecido en la resolución 2231 (2015) para reaccionar frente a «un incumplimiento significativo de los compromisos asumidos en el PAIC» como vía para desvincularse del PAIC y forzar la reimposición de las sanciones ${ }^{101}$. Como se ha indicado anteriormente, Trump había acusado a Irán en varias ocasiones de incumplir sus compromisos en virtud del PAIC. La resolución exige que se trate de un incumplimiento significativo, aunque no define qué ha de entenderse por tal. La aplicación del procedimiento, en caso de producirse la situación prevista en el par. 12 de la resolución (que no se apruebe una resolución para que siga en vigor la suspensión de las sanciones) comportaría la reanudación del régimen de sanciones contra Irán existente antes de la resolución 2231 (2015). No fue la opción seguida por Trump, que procedió a retirar a Estados Unidos del acuerdo unilateralmente.

\section{EL EXAMEN DE LA LEGALIDAD DE LAS SANCIONES DE ESTADOS UNIDOS POR LA CORTE INTERNACIONAL DE JUSTICIA}

Transcurridos poco más de dos meses desde la retirada estadounidense del PAIC, Irán interpuso una demanda ante la Corte Internacional de Justicia alegando posibles violaciones del Tratado de amistad, relaciones económicas y derechos consulares entre Estados Unidos e Irán, adoptado el 15 de agosto de 1955 y vigente desde 1957 (Tratado de amistad en lo sucesivo). La demanda de Irán solicitaba que la Corte declarara que las sanciones anunciadas por Estados Unidos el 8 de mayo violaban el Tratado de amistad entre ambos países, y que indicara que Estados Unidos debía poner fin a todas las sanciones e indemnizar a Irán por la violación de sus obligaciones internacionales. Simultáneamente, Irán introdujo ante la Corte una solicitud de medidas provisionales para obtener una orden exigiendo que Estados Unidos suspendiera las sanciones y permitiera realizar las transacciones autorizadas antes del 8 de mayo, con el objeto de evitar perjuicios irreparables a la economía de Irán ${ }^{102}$.

\footnotetext{
$101 \mathrm{Vid}$. S/RES/2231(2015), par. 11.

102 Alleged Violations of the 1955 Treaty of Amity, Economic Relations, and Consular Rights (Islamic Republic of Iran v. United States of America), Orden, 3 de octubre de 2018, disponible en https:// www.icj-cij.org/files/case-related/175/175-20181003-ORD-01-00-EN.pdf (en lo sucesivo, CIJ, Orden de 3 de octubre de 2018), par. 1-5.
} 
En la Orden sobre medidas provisionales adoptada el 3 de octubre de 2018, la Corte decidió por unanimidad adoptar algunas de las medidas provisionales solicitadas por Irán, tomando en consideración los derechos de ambas Partes.

\section{IV.1. La competencia prima facie de la Corte para conocer el caso}

Antes de indicar medidas provisionales, la Corte debe comprobar que tiene competencia prima facie para conocer el asunto, aunque sin necesidad de llegar a una conclusión definitiva acerca de su competencia para conocer el fondo ${ }^{103}$.

Irán invocó el artículo XXI.2 del Tratado de amistad de 1955 como base de la competencia de la Corte. De conformidad con el mismo:

«Any dispute between the High Contracting Parties as to the interpretation or application of the present Treaty, not satisfactorily adjusted by diplomacy, shall be submitted to the International Court of Justice, unless the High Contracting Parties agree to settlement by some other pacific means.»

Irán encaminó todos sus esfuerzos a demostrar que se trataba de una controversia relacionada con el Tratado de 1955. Según la argumentación iraní, el objeto de la controversia estaba constituido por las sanciones estadounidenses contrarias a algunas disposiciones del Tratado, por lo que la controversia versaba sobre la interpretación y aplicación del Tratado de amistad ${ }^{104}$. La argumentación iraní pretendía desvincular el objeto del litigio del PAIC, presentando la retirada de Estados Unidos del acuerdo como parte del contexto de la controversia, pero no como su objeto ${ }^{105}$.

${ }^{103}$ CIJ, Orden de 3 de octubre de 2018, par. 24.

${ }^{104}$ En particular, Irán invocó los artículos relativos al trato justo y equitativo (art. IV. Par.1), la prohibición de restricciones a medios de pagos y transferencias de fondos (art. VII.1); tratamiento conforme a la cláusula de nación más favorecida en la importación y exportación de determinadas categorías de productos (art. VIII.1 y 2 VIII) y a sus respectivos nacionales y entidades para actividades de importación y exportación (art. IX.2); prohibición de medidas discriminatorias en cuanto a la posibilidad de importadores (IX.3) y, la libertad de comercio (art. X.1). CIJ, Orden de 3 de octubre de 2018, par. 31 .

105 CIJ, Orden de 3 de octubre de 2018, par. 31. 
Estados Unidos, por el contrario, intentó demostrar que se trataba de una controversia referente el PAIC y a la decisión estadounidense de retirarse del mismo:

«Iran's Request for provisional measures is fundamentally an effort to restore the sanctions relief that the United States had provided when implementing the JCPOA. The Treaty of Amity is therefore simply a device in Iran's search for a jurisdictional basis to this Court.»106

El Plan de Acción, a diferencia del Tratado de amistad, no contenía ninguna cláusula compromisoria confiriendo competencia a la Corte Internacional de Justicia. Estados Unidos intentó demostrar que la Corte carecía de competencia desarrollando tres líneas argumentales. En primer lugar, que no se trataba de una controversia sobre la interpretación y aplicación del Tratado de amistad 1955. En segundo lugar, que la competencia de la Corte quedaría excluida en virtud las cláusulas del Tratado de amistad, referidas a posibles excepciones. En tercer lugar, que en el presente caso no se había cumplido la condición de la cláusula compromisoria del Tratado de 1951, que requiere que la controversia no haya sido satisfactoriamente resuelta antes de someter a controversia a la Corte.

En la primera línea de argumentación, Estados Unidos puso de relieve todos los aspectos que reconducían el caso a la aplicación y retirada del PAIC, entre ellos, la propia demanda de Irán, cuyo parágrafo 2 afirma:

«The present Application exclusively concerns the internationally wrongful acts of the USA resulting from its decision to re-impose in full effect and enforce the 8 May sanctions that the USA previously decided to lift in connection with the Joint Comprehensive Plan of Action» ${ }^{107}$

Estados Unidos, además, intentó justificar la retirada del PAIC y la consiguiente reintroducción de las sanciones suspendidas, como una decisión adoptada en respuesta a la conducta de Irán ${ }^{108}$. Así había quedado reflejado por el Presidente Trump en el Memorando de 8 de mayo de 2018 que men-

\footnotetext{
106 Alleged violations of the 1955 Treaty of Amity, Economic Relations, and Consular Rights (Islamic Republic of Iran v. United States of America), Verbatim Record, CR 2018/17 (en lo sucesivo CR 2018/17), p. 13.

107 CR 2018/17, pp. 14-20.

${ }^{108}$ CR 2018/17, p. 14.
} 
cionaba actuaciones como el apoyo de Irán a grupos armados en diferentes países de la región, para decidir que el interés nacional de Estados Unidos requería imponer nuevamente las sanciones del modo más expedito posible ${ }^{109}$.

En segundo lugar, Estados Unidos argumentó que las medidas anunciadas el 8 de mayo no constituirían en ningún caso una violación del Tratado de amistad porque entrarían dentro de las excepciones previstas en el artículo XX.1. Este último dispone que el Tratado no excluye la aplicación de medidas:

«(b) relating to fissionable materials, the radio-active by products thereof, or the sources thereof;

d) necessary to fulfill the obligations of the High Contracting Party for the maintenance or restoration of international peace and security, or necessary to protect its essential security interests» ${ }^{110}$

Las medidas de las Partes amparadas en esas cláusulas quedarían excluidas, según Estados Unidos, del ámbito de aplicación del Tratado y, por consiguiente, de la competencia de la Corte Internacional de Justicia. La interpretación estadounidense destacaba la flexibilidad de la formulación para defender que todas las sanciones que se pudieran adoptar para controlar o prevenir la proliferación nuclear podrían considerarse cubiertas por el apartado b) del art. XX.1. Del mismo modo, la decisión de restablecer las sanciones relacionadas con el programa nuclear de Irán, levantadas en aplicación del PAIC, que había sido justificada en el Memorando presidencial por razones de seguridad nacional, quedarían amparadas en la referencia del apartado d) a «intereses de seguridad esencial» ${ }^{111}$.

La Corte rechazó el argumento de Estados Unidos sobre el objeto de la controversia con un razonamiento que ya había seguido en el asunto de las plataformas petrolíferas ${ }^{112}$. La CIJ había señalado que el hecho de que la controversia hubiera surgido en el contexto de la retirada del PAIC y estuviera

\footnotetext{
${ }^{109}$ CIJ, Orden de 3 de octubre de 2018, par. 20.

$110 \ll$ Iran Initiates Suit Against the United States in the International Court of Justice, While Sanctions Take Effect», AfIL, vol. 113, n. 1, 2019, p. 176.

111 CIJ, Orden de 3 de octubre de 2018, par. 37.

112 Oil Platforms (Islamic Republic of Iran v. United States of America), Preliminary Objection, Judgment, I.C.F. Reports 1996 (II), pp. 811-812.
} 
relacionada con dicho instrumento no excluía que también afectara a la interpretación y aplicación del Tratado de amistad de 1955:

«In general terms, certain acts may fall within the ambit of more than one legal instrument and a dispute relating to those acts may relate to the «interpretation or application» of more than one treaty or other instrument. To the extent that the measures adopted by the United States following its decision to withdraw from the JCPOA might constitute violations of certain obligations under the 1955 Treaty, such measures relate to the interpretation or application of that instrument. $\gg^{113}$

Del mismo modo, la Corte ya había formulado su modo de interpretar las cláusulas b) y d) del artículo XX.1 del Tratado en el asunto de las plataformas petrolíferas, por lo que resultaba previsible el rechazo de la interpretación propuesta por Estados Unidos en sentido diferente. La Corte recordó que, en la decisión adoptada al respecto en 1996:

«took the view that Article XX, paragraph 1, subparagraph (d), did «not restrict its jurisdiction» in that case. It considered instead that that provision was «confined to affording the Parties a possible defence on the merits to be used should the occasion arise» (see Oil Platforms (Islamic Republic of Iran v. United States of America), Preliminary Objection, Fudgment, I.C.F. Reports 1996 (II), p. 811, para. 20)»114

Para Estados Unidos, las cláusulas tenían el efecto de excluir la competencia de la CIJ. Para la Corte, sin embargo, constituían excepciones que permitían a las Partes aplicar medidas formalmente en contradicción con los términos del Tratado pero lícitas si su adopción se ajustaba a las condiciones fijadas. Pronunciarse sobre la última cuestión, es decir, determinar si las medidas de Estados Unidos entraban dentro de las excepciones al Tratado en el presente caso, supondría ya un pronunciamiento definitivo sobre la competencia material de la Corte, y por lo tanto la $\mathrm{CIJ}$ consideró que no resultaba procedente entrar en esa cuestión en la fase de adopción de medidas provisionales ${ }^{115}$.

En la medida en que el Tratado de amistad contiene disposiciones en materia de libertad de comercio entre Irán y Estados Unidos, así como disposiciones específicas prohibiendo restricciones a las importaciones y exporta-

\footnotetext{
113 CIJ, Orden de 3 de octubre de 2018, par. 38.

114 CIJ, Orden de 3 de octubre de 2018, par. 41.

115 CIJ, Orden de 3 de octubre de 2018, par. 42.
} 
ciones entre ambos países, la Corte estimó que podía considerarse que las sanciones económicas adoptadas por Estados Unidos quedaban incluidas dentro del ámbito de aplicación material del Tratado ${ }^{116}$.

Entrando en la tercera línea de argumentación de Estados Unidos, el artículo XXI.2 del Tratado de amistad exige que la controversia sometida a la Corte no haya sido resuelta satisfactoriamente por medios diplomáticos. Se trataba, según la argumentación iraní, de una condición puramente objetiva y que se cumplía en la presente situación pues, efectivamente, la controversia no había sido resuelta por medios diplomáticos. Para Estados Unidos, por el contrario, se trataba de una condición de procedimiento que no había sido satisfecha en el presente caso. Desde esta perspectiva, la cláusula compromisoria exigiría que las Partes hubieran intentado verdaderamente resolver la controversia por medios diplomáticos, y que esas negociaciones estuvieran relacionadas con el Tratado invocado por el demandante como fundamento de la competencia ${ }^{117}$. La argumentación fuerza claramente los términos de la cláusula. La Corte resaltó que, a diferencia de las cláusulas compromisorias de otros tratados, la del Tratado de amistad no establecía una obligación de negociar como condición para someter el asunto a la Corte. En el presente caso, bastaba la constatación de que la controversia no había sido resuelta satisfactoriamente por medios diplomáticos, como era el caso ${ }^{118}$.

La Corte llegó a la conclusión de que el art. XXI. 2 del Tratado de amistad de 1955, le confería competencia prima facie para conocer la controversia.

IV.2. Plausibilidad de los derechos cuya protección se solicita y su conexión con las medidas adoptadas

La adopción de medidas provisionales de acuerdo con el artículo 41 del Estatuto de la CIJ requería adicionalmente una determinación previa de la

\footnotetext{
${ }_{116}$ CIJ, Orden de 3 de octubre de 2018, parrs 43-44.

117 CR 2018/17, pp. 28-32. Estados Unidos invocó en su apoyo las cláusulas compromisorias de otros Tratados así como pronunciamientos recientes de la Corte, entre otros en dos asuntos relativos a la Convención para la eliminación de todas las formas de discriminación sobre la eliminación, entre Georgia y Rusia, y entre Qatar y Emiratos Árabes Unidos (Application of the International Convention on the Elimination of All Forms of Racial Discrimination (Georgia v. Russian Federation), Preliminary Objections, Fudgment, I.C.7. Reports 2011 (I), p. 132, pará. 157; Application of the International Convention on the Elimination of All Forms of Racial Discrimination (Qatar v. United Arab Emirates), Provisional Measures, Order of 23 7uly 2018).

118 CIJ, Orden de 3 de octubre de 2018, par. 45-51.
} 
Corte en el sentido de que los derechos cuya protección se solicitaba eran plausibles. No se trataba de un pronunciamiento definitivo sobre la existencia de los derechos invocados sino de comprobar que tales derechos podrían ser contemplados en la decisión sobre el fondo ${ }^{119}$.

Las alegaciones presentadas por Irán y Estados Unidos en este ámbito giran, esencialmente, sobre los mismos razonamientos utilizados para fundamentar y rebatir, respectivamente, la competencia de la Corte. Irán se refirió a las disposiciones del Tratado ya mencionadas en su argumento sobre el objeto material de la controversia ${ }^{120}$. Estados Unidos reiteró que el objeto real de la demanda iraní era el PAIC y que, por consiguiente, Irán estaba solicitando la protección de unos derechos derivados del Plan de Acción y no del Tratado de amistad. La plausibilidad de los derechos de Irán quedaría igualmente excluida, según la argumentación estadounidense, como consecuencia de las excepciones previstas en el art. XX.1 b) y d) ${ }^{121}$.

En este punto, la Corte dio satisfacción parcial a las pretensiones de ambas partes. El Tratado de amistad confiere una serie de derechos en el ámbito del comercio y transacciones financieras tanto a Irán como a Estados Unidos. La plausibilidad de los derechos invocados por Irán debía ser ponderada en función de la plausibilidad de los derechos alegados por Estados Unidos en virtud de las cláusulas de exclusión establecidas en el art. XX.1. a) y b) ${ }^{122}$. La Corte concluyó que, en fase de adopción de medidas provisionales:

«some of the rights asserted by Iran under the 1955 Treaty are plausible in so far as they relate to the importation and purchase of goods required for humanitarian needs, such as (i) medicines and medical devices; and (ii) foodstuffs and agricultural commodities; as well as goods and services required for the safety of civil aviation, such as (iii) spare parts, equipment and associated services (including warranty, maintenance, repair services and safety-related inspections) necessary for civil aircraft.» ${ }^{123}$

La Corte también se pronunció favorablemente sobre la existencia de conexión entre los derechos invocados y las medidas solicitadas. Estados Unidos invocó nuevamente el PAIC para rechazar la existencia de conexión alegando

\footnotetext{
${ }^{119}$ CIJ, Orden de 3 de octubre de 2018, par. 53-54.

120 CIJ, Orden de 3 de octubre de 2018, parrs. 55-61.

${ }^{121} \mathrm{CIJ}$, Orden de 3 de octubre de 2018, par. 62-63.

122 CIJ, Orden de 3 de octubre de 2018, par 67-69.

123 CIJ, Orden de 3 de octubre de 2018, par. 70.
} 
que las medidas provisionales pretendían restaurar la aplicación del Plan de Acción. La Corte desestimó el argumento estadounidense. El razonamiento de la Corte fue hilando los aspectos relevantes para su conclusión. Irán había solicitado, entre otras medidas provisionales, la suspensión de las sanciones y el cumplimiento de las transacciones autorizadas antes del 8 de mayo. La Corte ya había determinado en otros apartados de la orden la plausibilidad algunos de los derechos invocados por Irán. En particular, había señalado como tales los relacionados con la importación y compra de bienes justificados por necesidades humanitarias, tales como medicinas y dispositivos médicos, alimentos y productos agrícolas, y bienes y servicios necesarios para la seguridad de la aviación civil. La Corte concluyó que algunos aspectos de las medidas solicitadas concernían a los derechos invocados por Irán ${ }^{124}$.

\section{IV.3. La existencia de un riesgo de un daño irreparable y urgencia}

Una última condición debía ser verificada antes de adoptar medidas provisionales: la concurrencia de un riesgo para Irán de sufrir un daño irreparable y la urgencia. Tras retirarse del PAIC, Estados Unidos había comenzado a adoptar medidas para restablecer las sanciones levantadas en virtud del Plan de Acción, de acuerdo con los dos plazos previstos. El último de ellos, 4 de noviembre de 2018, era inminente, y resultaba imposible que la Corte pudiera pronunciarse sobre el fondo del asunto antes de esa fecha. La urgencia de las medidas provisionales derivarían, para Irán, de esta consideración. Irán intentó demostrar además que las sanciones adoptadas por Estados Unidos creaban para Irán un riesgo de sufrir daños irreparables en ámbitos particulares como la seguridad en la aviación civil y la salud, y en la economía en su conjunto ${ }^{125}$.

Estados Unidos intentó demostrar la ausencia de urgencia en el presente caso subrayando que las medidas objeto de la controversia reintroducían medidas que ya habían sido aplicadas con anterioridad por Estados Unidos sin suscitar una reclamación similar por parte de Irán. En relación con el posible riesgo de daños irreparables a la economía iraní, Estados Unidos afirmó que el estancamiento económico iraní estaba causado por un conjunto de factores,

\footnotetext{
124 CIJ, Orden de 3 de octubre de 2018, par. 75-76.

125 CIJ, Orden de 3 de octubre de 2018, par. 80-83. Según la argumentación iraní, las excepciones humanitarias previstas por las diferentes normas estadounidenses no bastaban para cubrir las necesidades esenciales en los ámbitos de la seguridad de la aviación civil ni médico.
} 
entre ellos la inadecuada gestión del gobierno de Irán, por lo que no se podía evaluar el impacto concreto de la reimposición de sanciones. Estados Unidos cuestionó que de las sanciones pudieran derivarse daños a Irán en relación con la seguridad en la aviación civil y la salud, por la posibilidad de otorgar licencias en relación con el primer aspecto, y por la amplitud de las excepciones humanitarias contempladas en la legislación de referencia ${ }^{126}$. Por último, Estados Unidos alegó que la adopción de medidas provisionales causaría un perjuicio irreparable a «su derecho soberano» de aplicar su política respecto a Irán recurriendo a las medidas necesarias para proteger sus intereses esenciales en materia de seguridad, de acuerdo con el art. XXI.1 del Tratado de amistad ${ }^{127}$.

Los argumentos estadounidenses no hicieron mella en el razonamiento de la Corte. Los datos presentados a la Corte reflejaban con claridad que el anunciado restablecimiento de las sanciones estadounidenses ya había tenido repercusiones en el mercado. Con independencia de las excepciones previstas por la legislación estadounidense, las sanciones habían obstaculizado cualquier transacción comercial, dificultando la compra de bienes para satisfacer necesidades básicas.

\section{IV.4. Indicación de medidas provisionales y distanciamiento adicional de la Corte por parte de Estados Unidos}

Tras haber concluido que se reunían las condiciones para adoptar medidas provisionales, y en coherencia con las determinaciones previas sobre los derechos plausibles de las Partes, la Corte indicó, por unanimidad, tres categorías de medidas. En primer lugar, Estados Unidos debía retirar cualquier obstáculo para la exportación a Irán de: medicinas y dispositivos médicos; alimentos y productos agrícolas y las piezas de repuesto, equipos y servicios asociados necesarios para la seguridad en la aviación civil. En segundo lugar, Estados Unidos debía garantizar la concesión de todas las licencias y autorizaciones necesarias para que las transacciones relacionadas con los bienes y servicios antes mencionados no sufrieran restricción alguna. En tercer lugar, ambas Partes debían abstenerse de cualquier acción que pudiera agravar o ampliar la controversia, o hacer más difícil su solución ${ }^{128}$.

\footnotetext{
${ }^{126}$ CIJ, Orden de 3 de octubre de 2018, par. 84-86.

127 CIJ, Orden de 3 de octubre de 2018, par. 87.

128 CIJ, Orden de 3 de octubre de 2018, par. 102.
} 
Pocas horas después de hacerse pública la decisión, el Secretario de Estado, M. Pompeo anunció la retirada de Estados Unidos del Tratado de amistad. Una decisión, apuntó, adoptada con 39 años de retraso. Aunque el Tratado de amistad había quedado prácticamente en letra muerta desde la revolución islámica de 1979, había sido utilizado como base para plantear ante la Corte Internacional tres controversias entre ambos Estados, dos de ellas a iniciativa de Irán ${ }^{129}$. En este sentido, algunas de las conclusiones alcanzadas por la Corte no podían constituir una sorpresa para Estados Unidos. Como se ha ido señalando al analizar los diferentes aspectos, la Corte se pronunció en coherencia con su jurisprudencia previa y, en particular, con la interpretación que ya había realizado del Tratado de amistad de 1951 en las controversias anteriores entre Irán y Estados Unidos. No obstante, el Secretario de Estado ofreció una lectura de la orden sobre medidas provisionales que favorecía en gran medida a Estados Unidos. Por un lado, porque «la Corte había rechazado la pretensión iraní de conseguir medidas más amplias para interferir en las sanciones estadounidenses ${ }^{130}$. Por otro, porque las medidas indicadas se correspondían con actuaciones que Estados Unidos ya había venido aplicando:

«Existing exceptions, authorizations and licensing policies for humanitarian-related transactions and safety of flight will remain in effect. The United States have been actively engaged on these issues without regard to any proceeding before the Court» ${ }^{131}$

La terminación del Tratado por una de las Partes ${ }^{132}$ requiere que se respete un año de preaviso, por lo que la decisión de Estados Unidos no afectaría

${ }^{129}$ El Consejero de Seguridad Nacional, M. Bolton al anunciar, también el 3 de octubre, la retirada de Estados Unidos del Protocolo Opcional a la Convención de Viena sobre relaciones diplomáticas de 1961, señaló que la decisión de retirarse de ambos convenios se situaba en la línea de la política estadounidense de «consistente rechazo de la Corte Internacional de Justicia... politizada e ineficaz» («Trump Administration Announces Withdrawal...», op. cit., pp. 133-134.)

${ }^{130}$ Véase algunos extractos de la declaración, reproducidos en «Iran Initiates Suit Against the United States in the International Court of Justice, While Sanctions Take Effect», A7IL, 2019, pp. 173-182, en p. 177.

131 No obstante, Pompeo también mostró la decepción de Estados Unidos por el hecho de que la Corte no afirmara que carecía de competencia sobre cualquier aspecto relacionado con las sanciones estadounidenses (vid. «Iran Initiates Suit Against the United States...», op. cit., pp. 177178).

132 El artículo XXIII.2) y 3) del Tratado de amistad contempla la posibilidad de retirada de cualquiera de las Partes, transcurrido un año desde que lo hubiera comunicado por escrito a la otra Parte. 
a la competencia de la Corte para resolver el fondo del asunto, ni al contenido de la decisión ${ }^{133}$.

Si el asunto llega a las siguientes fases del procedimiento, la Corte tendrá que abordar cuestiones complejas. Entre ellas, el margen de discreción de las Partes para adoptar las excepciones al Tratado previstas en el art. XX.1. b y d (disposiciones que habían sido invocadas por Estados Unidos como fundamento jurídico de sus sanciones) y la competencia de la Corte para revisar tales medidas ${ }^{134}$. En el asunto de las plataformas petrolíferas, la Corte ya había afrontado la interpretación del art. XX.1. d) citando un pronunciamiento previo a propósito de una cláusula similar:

«the measures taken must not merely be such as tend to protect the essential security interests of the party taking them, but must be 'necessary' for that purpose»; and whether a given measure is «necessary» is «not purely a question for the subjective judgment of the party» (I.C.7. Reports 1986, p. 141, para. 282), and may thus be assessed by the Court.» ${ }^{135}$.

La resolución 2231 (2015) constituye un elemento relevante para la valoración jurídica de las sanciones de Estados Unidos. En un apartado previo, este trabajo proponía que dicha resolución no imponía una obligación jurídica de cumplir el PAIC y que, en este sentido, no representaba un obstáculo jurídico para la retirada unilateral. La resolución, sin embargo, había transformado sustancialmente el marco jurídico internacional que encuadraba la adopción de las nuevas medidas estadounidenses. Antes de la resolución 2231 (2015), el régimen de sanciones de Estados Unidos relativas al programa nuclear de Irán, contaba con el respaldo jurídico de las resoluciones 1696 (2006), 1737 (2006), 1747 (2007), 1803 (2008), 1835 (2008), 1929 (2010) y 2224 (2015) del Consejo de Seguridad. La resolución 2231 (2015) puso fin a las resoluciones mencionadas y debilita, por lo tanto en este sentido, la posición de que gozaba Estados Unidos anteriormente. La licitud de las medidas estadounidenses

${ }^{133}$ En caso de que la Corte llegara a pronunciarse sobre el fondo del caso, la decisión de retirada sí podría influir en la determinación de la eventual indemnización (en este sentido, «Iran Initiates Suit Against the United States...», op. cit., p. 178).

${ }^{134}$ Hill-Cawthorne, L., The ICF's Provisional Measures Order in Alleged Violations of the 1955 Treaty (Iran $v$ United States), ejiltalk, 3 de octubre de 2018, disponible en ejiltalk.org/the-icjs-provisional-measures-order-in-alleged-violations-of-the-1955-treaty-iran-v-united-states/.

135 Oil Platforms (Islamic Republic of Iran v. United States of America), Fudgement, I.C7. Reports 2003, par. 43. 
dependerá de que se ajusten efectivamente a las condiciones de proporcionalidad, necesidad y reversibilidad, derivadas del Derecho internacional y a las que puedan desprenderse, en este caso concreto, del Tratado de amistad.

El Secretario de Estado, en las declaraciones que acompañó al anuncio de la retirada del Tratado de amistad, no manifestó qué actitud adoptaría Estados Unidos ante las medidas indicadas por la Corte. Sus palabras daban a entender que la normativa y la actuación estadounidenses satisfacían plenamente las medidas indicadas por la Corte ${ }^{136}$. $\mathrm{Al}$ anunciar el comienzo de la segunda fase de la retirada del Plan de Acción y la plena reimposición de las sanciones, el Presidente Trump subrayó, significativamente, que «la venta de comida, medicina, dispositivos médicos y productos agrícolas a Irán ha estado durante largo tiempo, y sigue estando, exento de las sanciones» ${ }^{137}$.

\section{CONCLUSIONES}

El análisis realizado a lo largo del trabajo pone de manifiesto que la retirada unilateral del PAIC por parte de Estados Unidos no supone por sí misma una infracción de sus obligaciones jurídicas internacionales y no comprometería, por lo tanto, su responsabilidad internacional. Con esto no se quiere significar que las sanciones adoptadas por Estados Unidos sean lícitas en todo caso, cuestión que dependería de su conformidad con los requisitos fijados por el Derecho internacional.

El Plan de Acción Integral Conjunto carecía de valor obligatorio y su aprobación mediante la resolución 2231 (2015) tampoco habría tenido el efecto de conferirle naturaleza vinculante. La compleja técnica utilizada para dar forma y operatividad al PAIC, recurso a un instrumento no vinculante jurídicamente e incorporación del mismo a una resolución del Consejo de Seguri-

\footnotetext{
136 Para una síntesis del conjunto de sanciones de Estados Unidos a Irán, detallando los mecanismos para otorgar licencias y las excepciones humanitarias previstas, RENNACK, D.E., Iran: U.S. Economic Sanctions..., op. cit.; KaTZMAN, K., Iran Sanctions, op. cit., pp. 10, 37, 69-70.

137 Statement by the President Regarding the Reimposition of Nuclear-Related Sanctions on Iran, 2 de noviembre de 2018, disponible en https://www.whitehouse.gov/briefings-statements/statement-president-regarding-reimposition-nuclear-related-sanctions-iran/. La declaración mediante la que anunció la primera fase de las sanciones no formulaba una salvedad similar (Statement from the President on the Reimposition of United States Sanctions with Respect to Iran, 6 de agosto, 2018, disponible en https://www.whitehouse.gov/briefings-statements/statement-president-reimposition-united-states-sanctions-respect-iran/)
} 
dad, es reflejo de las circunstancias no menos complejas en que fue adoptado. Desde la perspectiva de la situación política de Estados Unidos, la oposición de un amplio sector del Congreso a la negociación del PAIC por Obama y la proximidad de elecciones no facilitaban un diseño claro de los objetivos del acuerdo. En la esfera internacional, las tensiones diplomáticas entre las Partes y el respaldo de la posición iraní por parte de Rusia, se tradujeron en divergencias sobre cuestiones clave del acuerdo que fueron formuladas con ambigüedad. Los defectos del PAIC resultaron más evidentes con el cambio de Administración en Estados Unidos.

Si bien no transformó los compromisos del PAIC en obligaciones para las Pares, la resolución 2231 (2015) ha tenido el efecto debilitar la posición de que disfrutaban antes de su adopción algunas de las sanciones de Estados Unidos. En efecto, las resoluciones del Consejo de Seguridad imponiendo sanciones a Irán en relación con el programa nuclear, garantizaban la licitud de las medidas nacionales adoptadas en el marco de las mismas. Al derogar estas resoluciones, la Resolución 2231 (2015) priva a las medidas de Estados Unidos de uno de los títulos para su adopción. Un aspecto que podría resultar relevante en caso de que la Corte se pronunciara sobre el fondo del asunto introducido por Irán contra Estados Unidos. 
